\title{
UNDERSTANDING HOW PRICE RESPONDS TO COSTS AND PRODUCTION
}

\author{
Mark Bils \\ Yongsung Chang \\ Working Paper 7311 \\ http://www.nber.org/papers/w7311
NATIONAL BUREAU OF ECONOMIC RESEARCH
1050 Massachusetts Avenue
Cambridge, MA 02138
August 1999

This paper was prepared for Carnegie-Rochester Conference Series on Public Policy, Spring 1999. We thank Dennis Carlton, Emin Dinlersov, Peter Klenow, Bennett McCallum, Valerie Ramey, Victor Rios-Rull, Richard Rogerson, and the discussant, Susanto Basu for helpful suggestions. The views expressed herein are those of the authors and not necessarily those of the National Bureau of Economic Research.

(C) 1999 by Mark Bils and Yongsung Chang. All rights reserved. Short sections of text, not to exceed two paragraphs, may be quoted without explicit permission provided that full credit, including $(\odot$ notice, is given to the source. 
Understanding How Price Responds to Costs and Production

Mark Bils and Yongsung Chang

NBER Working Paper No. 7311

August 1999

JEL No. E3

\section{ABSTRACT}

The importance of sticky prices in business cycle fluctuations has been debated for many years. But we argue, based on a large empirical literature from the 1950's and 60's, that it is necessary to distinguish the response of price to an increase in factor prices from its response to an increase in marginal cost generated by an expansion in production. Consistent with that earlier literature, we find for 450 U.S. manufacturing industries that prices do respond more to increases in costs driven by changes in factor prices than to increases in marginal cost precipitated by expansions in output. We explore two models that can potentially explain these findings. Both break the link between price and marginal cost, thereby generating what one might naively interpret as average-cost pricing. The first is driven by firms pricing to limit entry. The second is driven by firms pricing to limit non-price competition within their market.

Mark Bils

Department of Economics University of Rochester

Rochester, NY 14627 and NBER

bils@troi.cc.rochester.edu
Yongsung Chang

Department of Economics

University of Pennsylvania

McNeil 457, 3178 Locust Walk

Philadelphia PA 19104 


\section{Introduction}

Much work on business cycles has rested on the importance of price rigidities, both nominal and real, as a source of the size and frequency of fluctuations. These rigidities are often motivated by costs of one type or another in adjusting prices (e.g., Rotemberg, 1982a; Rotemberg, 1983). Consequently, recent empirical work on pricing often tests for costs of price adjustment by comparing the behavior of actual prices to behavior anticipated under perfectly flexible prices. Examples include Rotemberg (1982b), Carlton (1986), Cecchetti (1986), Kashyap (1995), Rotemberg (1995), and Sbordone (1998).

By contrast, an active empirical literature on pricing in the 1950's and 1960's was less connected to models of costly price adjustment. Authors estimated various versions of what Eckstein and Fromm (1968) refer to as the "price equation." These equations typically related prices freely to factor prices (labeled the cost factors) and to measures of the rate of production relative to capacity, such as output or the level of unfilled orders (labeled the demand factors). A fairly robust result of these earlier studies is that prices respond quite dramatically and rapidly to cost factors, and therefore average costs, but more weakly to output movements and their induced movements in marginal cost. Selected examples are Dow (1956), Wilson (1959), Klein and Ball (1959), Kuh (1959), Zarnowitz (1962), Neild (1963), Bodkin (1966), and Eckstein and Fromm.

More recent work has not overturned the consensus from this earlier literature that prices are very responsive to factor prices and average costs, but not to any induced movements in marginal cost from fluctuations in the rate of production. In fact, results from Blanchard (1987) and Roberts, et. al. (1994), who do allow for a differential response to cost and production factors, confirm the earlier findings.

If prices do respond sharply to cost factors, this puts considerable discipline on the extent and type of price rigidity. In particular, it implies that costs of price adjustment are not very important.

We can imagine three scenarios under which prices will respond to costs but not to production. The first is if marginal cost is essentially flat. The second scenario is if there is significant imperfect competition and the factors that influence the desired markup of price 
over marginal cost cause it to vary in a countercyclical fashion, offsetting the procyclicality of marginal cost. Rotemberg and Woodford (1991) review this line of research. The third scenario is that firms do not price with respect to marginal cost. It has often been argued that in practice firms price according to average, rather than marginal, cost. For instance, see Hall and Hitch (1939), Kaplan, et. al. (1958), and Blinder (1994). But these are attempts to describe firm pricing, as opposed to providing justification for such behavior. A large part of this paper is devoted to constructing a plausible model that generates pricing that looks like average cost pricing.

The paper proceeds as follows. In the next section we examine the response of industry prices to variations in costs and production for U.S. manufacturing. Our approach differs from past efforts in a couple of respects. We use more disaggregate, 4-digit SIC, industry data. We also exploit variations in total factor productivity (TFP) as a cost factor in addition to variations in factor prices. This allows us to address whether price fails to respond to demand because strong increasing returns makes marginal cost relatively flat. Like previous authors, we find industry price responds dramatically to cost factors. But this response is considerably less for movements in costs driven by TFP and wage movements than for movements driven by material and energy prices. By controlling for fluctuations in industry $T F P$, we find a much greater response of industry prices to production than do previous authors. Nevertheless, our results do support the notion that prices respond more sharply to variations in marginal cost due to cost factors than to similar sized variations in marginal cost driven by fluctuations in production. We also show that the response of price to production is much less in some industries than others. In particular, price responds much less in industries that are concentrated.

In Sections 3 and 4 we present two models potentially capable of generating such pricing. In both models firms compete with price in the market (Bertrand competition). We first consider, in Section 3, a limit-pricing model in which a dominant firm chooses price, not with respect to its own marginal cost, but in line with costs of a competitive fringe. Sylos (1957), Modigliani (1958), and McCallum (1969) each develop the idea that pricing to limit entry can generate something akin to average-cost pricing. We find that movements in marginal cost induced by output fluctuations are reflected in price only to the extent they are mirrored by movements in the costs of entrants. Furthermore, the response of price to TFP 
fluctuations depends on whether the TFP movements also hit potential entrants. We also examine how an economy with such pricing responds to economy-wide disturbances to technology and preferences. We find the model to be less promising for explaining price rigidity in aggregate. A general expansion, by driving up the cost of capital, tends to increase the costs of potential entrants as well as the marginal cost of incumbent firms, thereby influencing prices.

We next consider firms that limit their price markups in order to reduce costly expenditures among existing firms through non-price competition for market share. As this model is more novel, we develop it in detail in Section 4. We consider a setting in which firms have little incentive to cut price because each firm has an ongoing, understood policy of matching competitor's prices. As a result, price exceeds marginal cost. We then ask, what if firms can compete for buyers in dimensions other than price, such as through advertising, shorter checkout lines, or greater service? As discussed by Stigler (1968), firms will spend on these activities until the activity's marginal cost equals its impact on market share times the wedge between price and marginal cost. In choosing price, firms weigh the direct benefit of a higher industry price against the indirect cost that a higher markup will cause competing firms to spend more on attempts to gain market share. A key result is that, although price depends positively on marginal cost, it depends negatively on the slope of marginal cost. If marginal cost is both upward sloping and convex (to the origin) then price markups have a strong tendency to offset procyclical fluctuations in marginal cost. At the same time, prices will respond directly to factor prices. This model is more successful in general equilibrium in generating rigid prices that exacerbate output fluctuations in response to both technology and "demand-type" shocks. The model is also consistent with our observation that price responds less to production in industries that are both concentrated and engage in a lot of non-production activity.

\section{How Industry Prices Respond to Cost Factors and Production}

\section{The price equation}

Suppose output, $y_{t}$, is produced with a technology 


$$
\begin{aligned}
& y_{t}=f\left(a_{m t} m_{t}, a_{v t} v_{t}\right), \\
& v_{t}=\left[\alpha n_{t}^{\frac{\sigma-1}{\sigma}}+(1-\alpha) k_{t}^{\frac{\sigma-1}{\sigma}}\right]^{\frac{(1+\eta) \sigma}{\sigma-1}} .
\end{aligned}
$$

Where $m_{t}$ is a material input, and $v_{t}$ refers to value added produced from inputs of capital and labor. The function $f($ ) exhibits constant returns; but we will allow for increasing returns in the production of value added. $a_{m t}$ and $a_{v t}$ reflect technological changes that augment respectively materials and value added in production. The value added comes from a CES production function with returns to scale equal to $1+\eta$ and elasticity of substitution between capital and labor equal to $\sigma$.

The rate of growth in marginal cost, suppressing time subscripts, is given by

$$
\hat{m} c=\mu s_{m}\left(\hat{p}_{n}-\hat{a}_{n}\right)+\left(1-\mu s_{n}\right)\left(\hat{p}_{v}-\hat{a}_{v}\right) \text {. }
$$

Where a variable with a circumflex denotes that variable's rate of growth. $\mu$ equals the gross markup of price over marginal cost $(p / m c), s_{m}$ equals the cost of materials as a share of revenue. $p_{m}$ is the price of materials; $p_{v}$ is an implicit price, or marginal cost, of producing units of $v$. $p_{v}$ can be evaluated by the extra labor cost required to increase $v$ by one unit. This is convenient as it eliminates the need to measure movements in the effective cost of capital. This yields

$$
\hat{p}_{\nu}=\hat{w}+\frac{1}{\sigma}\left(\frac{s_{k}}{s_{n}+s_{k}}\right)\left(\frac{\hat{n}}{k}\right)-\eta\left(\frac{s_{n} \hat{n}+s_{k} \hat{k}}{s_{n}+s_{k}}\right) .
$$

$s_{n}$ and $s_{k}$ are the shares of labor and capital costs in revenue. Substituting into (3) gives

$$
\begin{aligned}
\hat{m} c=-\left[\mu s_{m} \hat{a}_{m}\right. & +\left(1-\mu s_{m}\right)\left(\hat{a}_{v}+\eta\left(\frac{s_{n} \hat{n}+s_{k} \hat{k}}{s_{n}+s_{k}}\right)\right]+\mu s_{m} \hat{p}_{m}+\left(1-\mu s_{m}\right)\left[\hat{w}+\frac{1}{\sigma} \frac{s_{k}}{s_{n}+s_{k}}\left(\frac{\hat{n}}{k}\right)\right] \\
& =-T \hat{F} P+\mu s_{m} \hat{p}_{m}+\left(1-\mu s_{m}\right)\left[\hat{w}+\frac{1}{\sigma}\left(\frac{s_{k}}{s_{n}+s_{k}}\right)\left(\frac{\hat{n}}{k}\right)\right]
\end{aligned}
$$

TFP refers to total factor productivity calculated with marginal cost shares of $\mu s_{m}$ and $\left(1-\mu s_{m}\right)$ respectively for materials and value-added inputs. For $\mu=1$, these reduce to average cost shares. 
There is a considerable literature directed at the question of whether cyclical movements in TFP reflect innovations to technology or the impact of increasing returns and imperfect competition (e.g., Hall, 1988). But for examining prices we do not need to make this distinction. The growth rate in TFP captures the effects of both technology change and increasing returns on variations in marginal cost.

Our focus is on examining the impact of cost factors versus fluctuations in production on prices. In terms of equation (5), we treat the cost factors as the growth rates in TFP and factor prices (both $p_{m}$ and $w$ ) while induced movements in marginal cost are captured by movements in the labor-capital ratio. Of course, to the extent procyclical TFP reflects increasing returns to scale, those movements in marginal cost are linked to variations in output. But increases in TFP will lower average cost as well as marginal cost. If capital is fixed or quasifixed in the short run, for instance because of internal adjustment costs (e.g., Lucas, 1967), then movements in $n / k$ will generate movements in marginal cost according to equation (5), but not comparable movements in average costs. This corresponds to firms with $\cup$-shaped short-run average cost curves.

For the empirical exercise, we first pick a value for the gross markup, $\mu$. We begin by setting $\mu=1$; but then explore robustness to values for $\mu$ as high as 1.5 . This allows us to construct the variables on the right hand side of equation (5). We then replace the growth in marginal cost in (5) with the growth in industry price. So we regress the growth rate in industry prices against the variables: $T \hat{F} P, \mu s_{m} \hat{p}_{m},\left(1-\mu s_{m}\right) \hat{w}$, and $\left(1-\mu s_{m}\right)\left(\frac{s_{k}}{s_{n}+s_{k}}\right)\left(\frac{\hat{n}}{k}\right)$.

$$
\hat{p}=-T \hat{F} P+\mu s_{m} \hat{p}_{m}+\left(1-\mu s_{m}\right) \hat{w}+\frac{1}{\sigma}\left(1-\mu s_{m}\right)\left(\frac{s_{k}}{s_{n}+s_{k}}\right)\left(\frac{\hat{n}}{k}\right)+(\hat{\mu}+e)
$$

The error term in the price equation reflects the growth rate in the price markup $(\hat{\mu})$ and measurement error $(e) .^{12}$ If movements in the markup are orthogonal to these right-hand-

\footnotetext{
${ }^{1}$ The markup variable $\mu$ multiplying the revenue shares in equation (6) is estimated as a parameter, though it is potentially varying over time. So the error also includes a term $\left(\frac{\mu-\bar{\mu}}{\mu}\right) \hat{m} c$ where $\bar{\mu}$ corresponds to the estimate of $\mu$. Also, we mcasure the rate of growth of a variable by the change in its natural log, that is, $\hat{x}=\operatorname{Ln}\left(x_{t} / x_{t-1}\right)$. Applying equation (6) in discrete-time
} 
side variables, then we should expect to obtain coefficients for these four variables of respectively $-1,1,1$, and $1 / \sigma$.

\section{Data}

We estimate the price equation with annual data for 1958 to 1994 for 458 4-digit SIC manufacturing industries. The data are from the NBER Manufacturing Productivity Database (Bartlesman and Gray, 1996), with much of it derived from the U.S. Annual Survey of Manufacturing. In estimating we include time dummies for each sample year. So the estimates are based on how an industry's relative growth rate in prices responds to relative industry growth rates in the right-hand-side variables, for example relative industry TFP growth. Material expenditures include expenditures on energy; and the industry price deflator for materials reflects movements in energy prices for the industry. We use the measure of TFP growth contained in the Database (again see Bartlesman and Gray), which is based on measuring separate factor inputs for non-energy materials, energy, labor, and capital. When allowing for $\mu>1$, we adjust the input weights in calculating the growth rate of TFP as dictated by equation (5).

Labor hours are measured by the sum of hours of production and non-production workers. There are no data on workweeks for non-production workers. We follow the Database's convention of setting the workweek for non-production workers equal to 40 . On a related note, average hourly earnings are based on dividing total wage and salary payments

introduces a small approximation error. These terms are captured in (6) as components of the measurement error term $e$.

${ }^{2}$ We examine the price equation in terms of annual growth rates. This renders the variables in equation (6) stationary; in fact the autocorrelations of the variables in growth rates are close to zero (Table 2, below). To examine whether a co-integrating relationship exists among price and the regressors in eqaution (6), we performed unit-root tests on the residuals from a regression in levels for each manufacturing industry. We were able to reject a unitroot in the residuals at the $5 \%$ significance level for only 87 of 458 industries. By examining annual growth rates, we also focus attention on short-run movements in prices and the right-hand-side variables. Where by short run we mean a period over which an industry's capital stock is relatively constant. 
by total labor hours. ${ }^{3}$ The results do not appear to be sensitive to reasonable alternatives, such as assuming variations in workweeks for non-production workers that are comparable to variations for the production workers. The NBER Productivity Database only includes the wage and salary costs of labor. In calculating labor's share, we magnify each 4-digit industry's wage and salary payments to reflect the importance of fringe payments and employer FICA payments in its corresponding 2-digit manufacturing industry. The ratio of these other labor payments to wages and salaries in the 2-digit industries, in turn, is based on information in the National Income and Product Accounts.

We calculate capital's share as value added's share in revenue minus labor's share. Previous studies (Rotemberg and Woodford, 1995; Basu and Fernald, 1997) have calculated that, given the low level of profits in manufacturing, this yields a result similar to direct attempts at measuring capital's share.

\section{Results}

Table 1 presents our results for the price equation. In all estimation we allow for the possibility that errors are heteroscedastic with respect to the regressors as well as with respect to the size of the industry (measured by sales). For this reason the estimation is by weighted least squares. The estimation places a slightly higher importance on larger industries. But in practice the results are extremely similar to those obtained by OLS.

\footnotetext{
${ }^{3}$ Bils (1987) argues that, with important costs of hiring or training workers (Oi, 1962), average hourly earnings poorly reflect the cyclical behavior of the marginal cost of labor. $\mathrm{He}$ finds that augmenting the average hourly wage for the marginal adjustment cost for labor or, equivalently, for the marginal impact of hours on overtime payments yields a much more procyclical measure for labor's effective price. Based on those results, we explored using fluctuations in an industry's workweek as a determinant of marginal cost. Prices respond positively to fluctuations in the workweek; but the impact on the other parameter estimates is minimal. The response of price to the workweek is far less than our calculation of its impact on marginal cost. Because fluctuations in the workweek may affect the marginal cost of labor while having little effect on average hourly earnings or average costs, this provides further support that price responds less to fluctuations in marginal cost that are not accompanied by comparable movements in average costs.
} 
We begin by assuming perfect competition: $\mu=1$. We subsequently consider price markups as large as 50 percent $(\mu=1.5)$. The results are qualitatively similar. (For $\mu=1$, note that $\left(1-\mu s_{m}\right)\left(\frac{s_{k}}{s_{n}+s_{k}}\right)\left(\frac{\hat{n}}{k}\right)$ reduces to $s_{k}\left(\frac{\hat{n}}{k}\right)$.

As a first step we ignore variations in TFP, so the growth rate in price is related to growth rates of material prices, wages, and the labor-capital ratio. We do this in order to be comparable to the large number of studies cited in the introduction that have not incorporated changes in TFP. Results appear in Table 1, Column 1. The impact of changes in the relative price of an industry's materials on growth in marginal cost is completely passed into the industry's relative rate of price increase. In fact, the output price increases by slightly more than one-for-one with the implied cost change, having a coefficient of 1.08 . By contrast, a 1 percent increase in an industry's relative average hourly earnings, weighted by $\left(1-s_{m}\right)$, is associated with an increase in the industry's relative output price of only .17 percent. Thirdly, a 1 percent increase in an industry's relative labor-capital ratio has an extremely small impact on an industry's relative price of .07 percent. Thus the results are consistent with findings in the literature that prices are much more related to factor prices than to fluctuations in production. But we also see a strikingly larger response to increases in material prices than to increases in wages.

Table 1, Column 2 presents results accounting for growth rates in industry TFP. As expected, relative industry shifts in TFP have a dramatic negative impact on relative industry price changes. But, in contrast with material price changes, the estimated magnitude of this impact, equaling -.51, falls well short of its anticipated impact.

Controlling for TFP growth dramatically increases the estimated response of price to an increase in wages or in the labor-capital ratio. A 1 percent increase in an industry's relative average hourly earnings, weighted by $\left(1-s_{m}\right)$, is now associated with an increase in the industry's relative output price of 49 percent. This is triple the magnitude in Column 1. However, this still falls far short of the anticipated value of 1 percent. A 1 percent increase in an industry's relative labor-capital ratio is now associated with a .54 percent rate of price increase. This is almost eight times the estimate obtained when ignoring industry TFP growth. Yet it remains far less than we would anticipate under a constant markup of price 
over marginal cost. The estimated coefficient of .54 is consistent with the impact of the labor-capital ratio on marginal cost only if the short-run elasticity of substitution between capital and labor is nearly 2. But research on production and factor demands suggests this elasticity is not significantly greater than one (Lucas, 1969, Hammermesh, 1986). So we should expect an estimated impact of $s_{k}(\hat{n})$ on rate of price change of 1 or greater.

The third column of Table 1 breaks materials into energy expenditures and expenditures on all other material inputs. Although expenditures on materials, on average, represent over half the value of gross revenue, energy expenditures constitute only a little over 2 percent. Price increases for energy have a slightly smaller impact on output prices than prices for other materials, receiving a coefficient of .94 compared to 1.09 for materials more generally. But this difference is not significant. From here forward, we do not distinguish energy inputs from other materials.

We find a much greater price response to material and energy price changes than to changes in TFP, wages, or the labor-capital ratio. One concern might be that these differential responses are created by measurement errors that, for some reason, are less important in measuring material and energy price changes than for the other factors. One might be particularly concerned about errors in measuring the rate of TFP growth, as its measurement requires an accurate measure of real output produced. ${ }^{4}$ For these reasons we estimate the price equation after first aggregating the 4-digit industry changes into corresponding 2-digit industries. If the measurement errors are largely uncorrelated across

\footnotetext{
${ }^{4} \mathrm{We}$ do eliminate 42 observations (out of 16,486) that report extreme rates of change in TFP of 40 percent or more in absolute value. A spuriously high measure of TFP should exaggerate the rate of TFP that year, but reduce its growth rate for the next. So one gauge of the importance of measurement error is the importance of a negative first-order moving average term in TFP growth. But we do not see evidence of this. In fact, the rate of TFP growth is slightly negatively related to its rate of growth two years before (coefficient of -.05 with standard error .008 ), but not at all to its growth rate the previous year (coefficient of -.01 with standard error .008). It is also unclear that measurement error in TFP growth biases its estimated effect on price change toward zero. Errors in measuring TFP growth reflecting errors in output measurement will tend to be associated with errors in measuring price changes of an opposite direction. So the bias is more likely in the direction of an estimated coefficient of -1 .
} 
industries, this should reduce the importance of measurement errors relative to true movements in the right-hand-side variables.

Results for estimation on the aggregated data appear in Column 4 of Table 1. Comparing to Column 2, the coefficients are all increased in magnitude, except that for the growth rate in TFP. The coefficient for material price changes is increased only modestly. The coefficient on wage changes is the most dramatically increased, rising from .49 in the 4digit data to .74 in the 2-digit data. This suggests that wage changes observed at the 4-digit industry level are either partly mismeasured or partly not allocative (as discussed in Hall, 1980). The coefficient for changes in the labor-capital ratio rises from .54 to .65. We view this estimate as still small relative to the anticipated impact of an increase in the laborcapital ratio on marginal cost.

Table 2 presents the standard deviation and autocorrelation for the dependent variable as well as the four right-hand-side variables. (All variables reflect the residuals after removing the impact of time-period dummies.) Models of costly price adjustment typically predict a greater response of price to persistent than temporary changes in factors. Changes in material prices, which receive the largest coefficient in Table 1, are the most persistent of the factors influencing marginal cost. However, increases in the labor-capital ratio are also extremely persistent, with the growth rate in $n / k$ positively correlated with its prior growth rate. Increases in TFP and wage rates are also quite persistent.

In estimating we include time dummies for each sample year. So the estimates are based on how an industry's relative growth rate in price responds to its relative industry growth rates in TFP, material prices, wages, and labor-capital ratio. The results, however, are not sensitive to this choice. Omitting the time dummies, yields very similar results to those in Table 1, Column 2. More exactly, the rate of material price change receives a coefficient a little greater than 1 , and growth rates in TFP, wages, and the labor-capital ratio each receive coefficient of about 0.5 in absolute magnitude.

To this point we have imposed a gross markup of price over marginal cost of one $(\mu=1)$. From equation (6), we see that the coefficient on material price changes is directly scaled by $\mu$, whereas the coefficients on wage changes and changes in the labor-capital ratio 
is scaled by $\left(1-\mu s_{m}\right)$. Therefore, it is worth asking if the large coefficient on material price changes, compared to the other factors in equation (6), is due to understating the value of $\mu$.

In Table 3 we reexamine results for equation (6), increasing parameter $\mu$ from 1 to 1.25 , and finally to 1.5 . The first column of the Table, for $\mu=1$, simply repeats Column 2 of Table 1. Turning to Column 2, increasing $\mu$ from 1 to 1.25 does reduce the coefficient on material price changes from 1.09 to .92 . The coefficients for the other factors, however, are little affected, remaining about .5 in absolute magnitude. Raising $\mu$ higher to 1.5 further reduces the coefficient on material price changes to .80 . But again the coefficients on the other parameters do not increase. In fact, the coefficient on the growth rate in the laborcapital ratio is actually reduced to .44 . It may appear surprising that raising the value of $\mu$ can reduce this coefficient, given that the growth rate of the labor-capital ratio is multiplied by $\left(1-\mu s_{m}\right)$ in equation (6). It is necessary to keep in mind, however, that the definition of TFP growth varies as we raise $\mu$ going across the columns in Table 3 . Higher values of $\mu$ place a higher weight on material input and a lower weight on labor and capital in calculating TFP. This serves, indirectly, to lower the coefficient on the growth rate of the labor-capital ratio.

Our conclusion, based on Table 3, is that price changes project much more on material price changes, compared to changes in the other factors, over the entire range of plausible values for $\mu$.

In the introduction we refer to a large older empirical literature that estimated price equations. These studies typically included one or more lagged prices on the right-hand side. Models of costly price adjustment rationalize including lagged and expected future prices as determinants of current prices. For this reason, we briefly explore including past and future industry price changes as determinants of the current year's price change.

Table 4, Column 1 includes last year's rate of industry price change as a regressor. It is statistically very significant, but has only a small impact on this year's price change, with 1 percent higher price inflation the previous year associated with .07 percent higher inflation this year. The estimated coefficients for the factors determining the rate of growth of marginal cost are little changed from their values in Table 1. With costs of price changes, 
next year's expected price change, generally speaking, should influence this year's as well. For example, with convex costs of price adjustment (e.g., Rotemberg, 1982b) the estimated coefficient on next year's expected price change should be nearly as large as that for last year's price change. In the second column we include next year's expected rate of price change, where the expectation reflects instrumenting for the $t+1$ price change with the rate of growth in the cost and demand factors from $t, t-1$, and $t-2$, and the output price change from $t-1$ and $t-2$. The estimated impact of last year's rate of price change is somewhat larger than when introduced alone in Column 1, now receiving a coefficient of 09 . The expected rate of price change for the next year exhibits a similar impact, receiving a coefficient of 10 .

\section{Cyclical capital utilization and overhead inputs}

We have allowed for movements in industry TFP arising from non-constant returns as well as shifts in technology. In either scenario price should grow one percent less for each one percent increase in TFP. But we have seen that one percent faster annual TFP growth is associated with only about 0.50 percent lower price inflation.

It has often been suggested that cyclical movements in TFP reflect procyclical, unmeasured, variations in the utilization of inputs, particularly capital. In an appendix we allow for movements in TFP that derive from varying utilization of capital or, alternatively, from increasing returns due to overhead inputs of labor and capital. In both cases we still predict that price movements should display a coefficient of -1 (or very nearly -1 ) with respect to TFP movements. We do find, for both extensions, that the coefficient on $\left(\frac{\hat{n}}{k}\right)$ is biased from

$1 / \sigma$. In neither case, however, does this suggest finding a coefficient on $\left(\frac{\hat{n}}{k}\right)$ of less than one. Therefore, we do not see these extensions as promising for explaining the results presented in Table 1.

\section{Cross-Industry Results}

In this section we examine results for the pricing equation separately by industry and ask whether industry characteristics, such as the presence of large firms, predict less 
response of price to production. Below we develop models aimed at explaining why firms might price in a way that resembles average-cost pricing. Both models we consider, pricing to limit entry and pricing to limit non-price competition, require departing from competitive marginal cost pricing. So it is natural to ask whether characteristics we associate with less than perfect competition are associated with the failure of price to respond to fluctuations in $s_{k}(\hat{n})$

We begin in Table 5 by listing the results for price equation (6) estimated separately by major industry. More exactly, the 16,444 observations (at the 4-digit SIC industry level) are first grouped into corresponding 2-digit industries, then separate equations are estimated for each of these 20 industries. We focus in Table 5 on estimated coefficients for the variable $s_{k}\left(\frac{\hat{n}}{k}\right)$. We note, however, that price is responsive to the factors determining marginal cost for each industry. In particular, the variable representing growth in material prices, $s_{m} \hat{p}_{m}$, receives an estimated coefficient greater than 0.5 in every one of the 20 industries and greater than 1.0 in most. Looking at Table 5, we see the coefficient estimate for $s_{k}(\hat{n})$ varies considerably across the 20 industries. The table has industries sorted in descending order of this estimated coefficient. Industry prices are most responsive to $s_{k}\left(\hat{\frac{n}{k}}\right)$ in the primary metals, lumber, and food industries. Each industry exhibits an estimated response of greater than 0.70 . The three industries furniture, printing, and tobacco display the least response of prices to $s_{k}\left(\hat{\frac{n}{k}}\right)$; each exhibits an estimated response of less than 0.30 .

We next ask whether price is less likely to respond to $s_{k}\left(\frac{\hat{n}}{k}\right)$ if an industry has production concentrated in a few firms or if the industry expends significant resources on non-production activity. These variables are natural for us to consider given the models explored in Sections 3 and 4. Both models rely on a less than competitive environment. In the limit-pricing model of Section 3 this reflects the greater productivity of a market leader. Taken literally, that model implies a single producing firm in an industry. The model of Section 4 relies on the ability of firms to match competitor's prices. The connection to industry concentration is less clear, but we would expect the implicit collusion from price 
matching to be more relevant with fewer competing firms. This model links the failure of price to respond to $s_{k}\left(\frac{\hat{n}}{k}\right)$ directly to the importance of spending on marketing and services designed to influence market share. We view the importance of non-production workers as a rough proxy for these activities.

We measure the concentration of an industry's production by the industry's 4-firm concentration ratio for value added in 1987. For a price change from year $t$ to $t+1$, we measure the importance of non-production workers by the average of the shares of nonproduction workers in employment for year $t$ and $t+1$

Table 6, Column 1 presents results for the pricing equation now interacting $s_{k}\left(\frac{\hat{n}}{k}\right)$ with the deviation of an industry's concentration ratio from its average over all industries of .40 . We see that a high concentration ratio is associated with a significantly smaller response in price to $s_{k}(\hat{n})$. This effect is both quantitatively and statistically significant. For instance, for the chewing gum industry, which has a concentration ratio of 96 , the result suggests that price will increase by only 0.39 percent in response to an increase in $s_{k}\left(\frac{\hat{n}}{k}\right)$ of one percent. This compares to a response of .55 percent anticipated for an industry with the average concentration ratio of 40 .

The second column of Table 6 additionally includes a regressor reflecting an interaction of $s_{k}(\hat{n})$ with the deviation of an industry's non-production employment share from its overall average of .25 . The regression shows that a higher ratio of non-production workers is associated with less response in price to $s_{k}\left(\frac{\hat{n}}{k}\right)$. But this result is not statistically significant.

\section{Summary and discussion}

We find support for the notion that shifts in cost factors are associated with greater responses in output prices than are comparable changes in marginal cost created by fluctuations in production. Each percent increase in $s_{k}\left(\frac{n}{k}\right)$ is associated with a price 
response of only about .50 percent. Under a constant price markup, this only makes sense if the short-run elasticity of substitution between capital and labor is about 2 , which seems implausibly large. Furthermore, the response in price is less in concentrated industries.

By contrast, increases in marginal costs generated by increases in the prices of material or energy inputs are associated with one-for-one increases in output prices. We find an important distinction, however, between these cost factors and the rates of growth in TFP and average hourly earnings. Changes in these latter cost factors are associated with important movements in prices, but with a magnitude only about half their impact on marginal cost.

We have argued that the markup is not constant. In particular, increases in the laborcapital ratio appear to be correlated with decreases in the price markup, yielding a coefficient that is much less than one for $s_{k}\left(\frac{\hat{n}}{k}\right)$. It should be clear, however, that we have only produced estimates of how changes in prices project on changes in the labor-capital ratio. We have not estimated a structural response of the markup to an increase in production. In particular, the exercise is silent on whether increases in production create a cut in the markup in the short run (as in the models below), or perhaps shifts in price markups due to an other factors are associated with increases in production.

To better get at causality, one ideally would instrument for movements in production with variables orthogonal to other potential sources of movement in an industry's price markup. We do not see an obvious way to effectively instrument for all the factors in our equation (6). Hall (1991), Shea (1993), and Bils and Klenow (1998) each instrument for fluctuations in production. Hall employs oil, military spending, and political variables as instruments. Shea employs production in industries that are downstream users of an industry's production. Bils and Klenow use the durability and cross-sectional Engel curve of the consumer good produced in an industry, interacted with aggregate fluctuations in consumption.

Each study finds that instrumented increases in production are associated with important increases in price. Less emphasis is placed on the behavior of the price markup. Hall assumes a constant markup. Shea's estimates suggest a significant fall in the markup 
for the first nine, or so, months of an expansion. But typically the markup completely recovers soon after. Bils and Klenow find that instrumented increases in production are associated with very significant increases in the wage rates and material prices paid in an industry. After accounting for these changes in factor prices, their results imply that a shortrun expansion in production is associated with a significant fall in the price markup.

\section{Limit Pricing}

To explain this behavior of prices a model should generate a greater price response to increases in marginal cost associated with cost factors than to those arising from expansions in labor and output. Ideally, the model should also predict a weaker response for fluctuations in costs generated by changes in TFP or wages than for changes in other factor prices. In this section we examine a limit-pricing model in which a dominant firm in each industry sets price just low enough to keep out a fringe of potential competitors. The model results in average cost pricing. Furthermore, we can rationalize a weaker response of price to TFP and wages than to other factor prices if variations in TFP and wages for the dominant firm are not shared completely by the fringe of potential entrants.

We begin by laying out the general economic environment in which firms operate. This setting is sufficiently general to allow for perfect competition, limit pricing, or the model of pricing to limit expenditures aimed at market share that we examine in Section 4. We then introduce assumptions that generate firms pricing to limit entry. Finally, we examine, by means of impulse responses, how that economy responds to business cycles driven by shocks to technology or by shifts in preferences that affect market demand.

\section{General equilibrium setting}

There are a large number of identical infinitely lived consumers in the economy. The representative consumer maximizes expected discounted utility defined over a stream of consumption, $C_{t}$ and leisure, $1-N_{t}-S_{t}$ where $N_{t}$ is hours worked and $S_{t}$ is shopping time (see Section 4 below). 


$$
\left.\max _{\left\{C_{t+\tau}, N_{t+\tau}\right\}_{\tau=0}^{\infty}} E_{t} \sum_{\tau=0}^{\infty} \beta^{\tau} u\left(C_{t+\tau}, 1-N_{t+\tau}-S_{t+\tau} ; \theta_{t+\tau}\right)\right]
$$

where $\quad u\left(C_{t}, 1-N_{t}-S_{i} ; \theta_{t}\right)=\theta_{t} \log C_{t}+\left(1-\theta_{t}\right) \frac{\left(1-N_{t}-S_{t}\right)^{1-\gamma}}{1-\gamma}$,

$$
C_{t}=J^{\frac{1}{1-\varepsilon}}\left[\sum_{j=1}^{J} C_{t}(j)^{\frac{\varepsilon-1}{\varepsilon}}\right]^{\frac{\varepsilon}{\varepsilon-1}}, \varepsilon>0
$$

$E_{t}$ is the expectation operator; the discount factor is $\beta$. Consumption reflects a CES aggregate of commodity varieties $\left\{C_{t}(j)\right\}_{j=1, \ldots,}$, with substitution elasticity $\varepsilon$. Shifts in preferences between purchased goods and leisure are allowed through variations in $\theta_{t}$. The ownership of firms is evenly distributed across consumers, with $\pi_{t}(i, j)$ representing the profit made by firm $i$ in industry $j$. The discount factor, as of $t$, for nominal expenditures incurred at $t+\tau$ is $\omega_{t \tau}=1 /\left[\left(1+R_{t}\right)\left(1+R_{t+1}\right) \ldots\left(1+R_{t+t-1}\right)\right]$ for $\tau>0$ and $\omega_{t 0}=1$, where $R_{t}$ is the nominal interest rate. Denote the nominal wage by $W_{t}$ and the price of consumption good $j$ by $P_{t}^{c}(j)$. Then the consumer's lifetime budget constraint is

$$
E_{t}\left[\sum_{\tau=0}^{\infty} \omega_{t \tau}\left(\sum_{j} P_{t+\tau}^{c}(j) C_{t+\tau}(j)\right)\right]=E_{t}\left[\sum_{\tau=0}^{\infty} \omega_{t \tau}\left(W_{t+\tau} N_{t+\tau}+\sum_{i, j} \pi_{t+\tau}(i, j)\right)\right]
$$

The intratemporal and intertemporal first order conditions are

$$
\begin{aligned}
& \frac{u_{2}\left(C_{t}, 1-N_{t}-S_{t}\right)}{u_{1}\left(C_{t}, 1-N_{t}-S_{t}\right)}=\frac{W_{t}}{P_{t}^{c}}, \\
& u_{1}\left(C_{t}, 1-N_{t}-S_{t}\right)=E_{t}\left[\left(1+R_{t}\right) \frac{P_{t}^{c}}{P_{t+1}^{c}} \beta u_{1}\left(C_{t+1}, 1-N_{t+1}-S_{t+1}\right)\right],
\end{aligned}
$$

where $P_{t}^{c}=\left[J^{-1} \sum_{j=1}^{J} P_{t}^{c}(j)^{1-\varepsilon}\right]^{1 /(1-\varepsilon)}$.

Firm $i$ in industry $j$ maximizes the discounted profit

$$
E_{t}\left[\sum_{\tau=0}^{\infty} \omega_{t \tau} \pi_{t+\tau}(i, j)\right]
$$

where

$$
\pi_{t}(i, j)=p_{t}(i, j) y_{t}(i, j)-W_{t} l_{t}(i, j)-P_{t}^{x} x_{t}(i, j)-W_{t} M_{t}(i, j)
$$




$$
\begin{aligned}
& k_{t+1}(i, j)=x_{t}(i, j)+(1-\delta) k_{t}(i, j), \\
& x_{t}(i, j)=J^{\frac{1}{1-\varepsilon}}\left[\sum_{k=1}^{j} x_{t}(i, j, k)^{\frac{\varepsilon-1}{\varepsilon}}\right]^{\frac{\varepsilon}{\varepsilon-1}}, \varepsilon>0, \\
& P_{t}^{x}=\left[J^{-1} \sum_{j=1}^{J} P_{t}^{x}(j)^{1-\varepsilon}\right]^{1 /(1-\varepsilon)} .
\end{aligned}
$$

The firm chooses price $p_{t}(i, j)$, production labor $l_{t}(i, j)$, marketing labor $M_{t}(i, j)$ (see Section 4), and investment $x_{t}(i, j)$. Capital is accumulated through investment $x_{t}(i, j)$, which aggregates variety of intermediate goods $\left\{x_{l}(i, j, k)\right\}_{k=1, \ldots, j}$ in a CES fashion with the same substitution parameter $\varepsilon$ as for consumers. The depreciation rate of capital is $\delta$.

Optimal investment satisfies the Euler equation

$$
E_{l}\left[\frac{\partial \pi_{t+1} / \partial k_{t+1}}{P_{t+1}^{x}}+1-\delta\right]=E_{t}\left[\left(1+R_{t}\right) \frac{P_{t}^{x}}{P_{t+1}^{x}}\right]
$$

The marginal profit from an additional unit of capital can be evaluated by the implied cost reduction in labor purchases, $\frac{\partial \pi_{t+1}}{\partial k_{t+1}}=W_{t+1} \frac{M P K_{t+1}}{M P L_{t+1}}=W_{t+1} \frac{(1-\alpha) l_{t+1}}{\alpha k_{t+1}}$.

General market clearing requires that total labor supplied be equal to the sum of production and marketing labor demanded by firms.

$$
N_{t}=\sum_{i, j} l_{t}(i, j)+\sum_{i, j} M_{i}(i, j)
$$

Also, in each goods industry supplies and demands must be equal.

$$
\sum_{i} y_{t}(i, j)=C_{t}(j)+\sum_{i, k} x_{t}(i, k, j) \text { for } j=1, \ldots, J
$$

\section{Pricing to Limit Entry}

Limit pricing implies that the best-technology firm charges the price at the minimum of average cost of the second best firm (See Figure1). Denote the productivity index of the 
best firm and the second best firm in industry $j$ as $a(1, j)$ and $a(2, j)$, respectively. The markup ratio in industry $j$ is

$$
\mu_{t}(j)=\frac{a c_{t}(2, j)}{m c_{t}(1, j)}
$$

where $a c$ and $m c$ denote average cost and marginal cost, respectively.

Suppose the production function exhibits a Cobb-Douglas technology, $y_{t}(i, j)=a_{t}(i, j) k_{t}(i, j)^{1-\alpha} l_{t}(i, j)^{\alpha}$, and that there is neither marketing effort on the firms' part, $M_{t}(i, j)=0$, nor shopping effort on the consumers', $S_{t}=0$. The (short-run) marginal cost of the existing firm is (with normalization of $W$ to 1 )

$$
m c_{t}(1, j)=\alpha^{-\alpha}(1-\alpha)^{-(1-\alpha)}\left(\frac{l_{t}(1, j)}{k_{t}(1, j)}\right)^{1-\alpha} a_{t}(1, j)^{-1} .
$$

We treat the capital stock for the incumbent firm, $k_{t}(1, j)$, as given during $t$, with investment during $t$ dictating $t+1$ 's capital stock. In essence we are assuming that acquiring and operating additional capacity during $t$ is prohibitively expensive reflecting internal costs of adjustment. This is the source of a short-run $\cup$-shaped average cost curve, and an upward sloping marginal cost curve, for the incumbent.

By contrast, we assume the potential-entrant firm can purchase capital in order to produce within the time period. (More exactly, an entering firm can use the CES technology to form a unit of current capital from a variety of current intermediate goods.) Thus an entrant is not tied to any preexisting level of capacity. The average cost of a second-best technology firm is

$$
a c_{l}(2, j)=\alpha^{-\alpha}(1-\alpha)^{-(1-\alpha)} Q_{i}^{1-\alpha} a_{i}(2, j)^{-1}
$$

where $Q_{t}$ is the effective rental price of capital for entrants. (Note that this also equals the marginal cost for an entrant-see Figure 1.) The rental price is calculated as $Q_{t}=q_{t} P_{t}$, where $q_{t}$ is the implicit real rental rate that an entrant would equate to $M P K_{t}$. This rental 
rate is given by $q_{t}=\frac{r_{t}^{e}+\delta}{1+r_{t}^{e}}$, where $r_{t}^{e}$ is the expected real interest rate for the economy from $t$ to $t+1 .^{5}$

In a symmetric equilibrium with $J$ normalized to $1, y_{i}(i, j)=Y_{t}, k_{t}(i, j)=K_{t}$, $x_{t}(i, j)=X_{t}, C_{t}(j)=C_{t}, l_{t}(i, j)=L_{t}, P_{t}^{c}(j)=P_{t}^{x}(j)=P_{t}^{c}=P_{t}^{x}=P_{t}, a_{t}(1, j)=A_{t}(1)$, $a_{t}(2, j)=A_{t}(2)$, and so forth. Of primary interest, the common markup is given by

$$
\mu_{t}=\frac{Q_{t}^{1-\alpha}}{\left(L_{t} / K_{t}\right)^{1-\alpha}} \frac{A_{t}(1)}{A_{t}(2)}
$$

Note first of all that the bigger is the technology gap between the leader and the follower, the bigger is the markup. Related to this, price and output respond very differently to a productivity shift depending on whether it hits just the best-technology, incumbent firm, just the potential-entrant firm, or both. Figure 2 displays the response to a technology increase for the potential entrant. This has no impact on productivity in actual production. It does act to lower the incumbent's price, thus creating a negative markup shock. In sharp contrast, Figure 3 displays an improved technology for the best-technology firm. This lowers marginal and average cost but leads to no decrease in price, thus directly increasing the markup.

The markup also varies with the ratio of the rental price of capital to the labor-capital ratio. Consider a transitory increase in $L_{t} / K_{t}$. A high current ratio of labor to capital is associated with a high marginal cost for the best-technology incumbent. But, if this increase is transitory, that implies the rental price on capital has gone up by less than the current ratio $L_{k} / K_{t}$. Therefore average costs for a potential entrant rise by less than the best firm's marginal cost, creating a decrease in the markup.

${ }^{5}$ An entrant's first-order condition determining demand is $E_{t}\left[M P K_{t} \frac{\left(1+R_{t}\right) P_{t}}{P_{t+1}}+1-\delta\right]=1+r_{t}^{e}$. The left side is the gain in terms of output in $t+1$ of putting $P_{t}$ dollars in capital. 


\section{Response to economy-wide shocks}

We examine the response of the limit-pricing economy to shocks to technology, either to the incumbent or the potential entrant, and to preferences through the parameter $\theta_{t}$. In both the technology and preference shocks we assume the disturbances follow a firstorder autoregressive process with an $\mathrm{AR}(1)$ parameter of 0.9 for quarterly observations. We produce impulse responses based on log-linear approximations to the model's first-order conditions.

We adopt values for labor share, the discount factor, and the depreciation rate that are commonly used in the literature: $\alpha=2 / 3, \beta=.99, \delta=.025$. We choose a steady-state value for $\theta$ so that the steady-state hours of work $N$ equal 1/3. For $N=1 / 3$, we choose $\gamma=2$ in order that the compensated labor supply elasticity equals 1 . We set the substitution elasticity of goods $\varepsilon$ equal to 1.3784 . This is not important for the results for the limitpricing model, but yields a steady-state price markup of 50 percent for the model in Section 4. All parameters remain the same for examining the non-price competition model in Section 4 , with the exception of $\sigma$, the elasticity of capital-labor substitution in production. Here we assume $\sigma=1$ (Cobb-Douglas). We consider modestly smaller values in Section 4. The calibrated parameter values are summarized in Table 7.

Figures 4 through 6 display the economy's response to technology shocks. Figure 4 treats the case of a common increase in technology of one percent. That is, $a$ increases by one percent for potential entrants as well as for the incumbent firm. The economy's response is fairly standard. Output increases initially by 1.4 percent, with much of this increase occurring through investment spending. Marginal cost (expressed relative to the normalized wage) falls by somewhat less than one percent, reflecting the initial rise in the labor-capital ratio of 0.6 percent. The rental price of capital, which is mirrored in the following period's labor-capital ratio, rises somewhat less than the implicit value of capital to incumbent firms. Therefore the costs for potential entrants rise by less than do marginal costs for incumbents. This results in a small drop, a 0.1 percent decrease, in the markup. The relatively small decrease in the markup reflects the high persistence of the technology shock, and the persistent response it generates in the labor-capital ratio. For instance, if we 
consider a one percent technology shock with an autocorrelation of .2 , rather than .9 , the drop in the markup is much larger, equaling 0.7 percent for the first quarter.

Figure 5 shows the response of the economy to a one percent increase in technology that affects incumbent firms, but does not affect potential entrants. Because costs for entrants are little affected, price is almost unchanged. The markup rises by a full one percent. The rise in the markup mutes to some extent the impact of the productivity increase on production. Labor input actually falls by a quarter percent. Recent papers by Gali (1999) and Basu, et. al. (1998) estimate that technology shocks and inputs are actually negatively correlated. All three papers point to sticky prices as an explanation for this finding. We obtain a negative correlation here despite prices being flexible. To the extent that increases in productivity do not extend to potential competitors, price responds as though it is sticky.

In Section 2 we found that industry prices responded only about half as much to industry TFP movements as expected. If we view the shocks to productivity that buffet producers as roughly an equal mixture of those that hit potential competitors (as in Figure 4) and those that do not (Figure 5), this would rationalize those findings in Section 2.

The case of an increase in technology for potential entrants, not relevant for the current producer, is given in Figure 6. This acts like a pure markup shock, as studied, for instance, by Rotemberg and Woodford (1995). Price falls (relative to the wage) despite a rise in marginal cost. The markup drops by a full percent in the first quarter and remains persistently low, resulting in a sustained expansion in hours and output.

According to the empirical analysis in Section 2, output price closely reflects the changes in marginal costs induced by material prices. An increase in input prices other than capital and labor is equivalent to a decrease in productivity, $a$, in our production function. Assuming changes in material prices affect the incumbent and potential entrant firms equally, then the response of output price to a decrease in material price is very similar to its response to a common productivity increase for both incumbent and fringe firms. To distinguish the material price change from the economy-wide productivity increase, which has an effect on the real interest rate, we examine the response of an industry in a partial equilibrium environment. The response is very similar to that in Figure 4 for the common 
productivity shock. Consistent with the findings in empirical analysis, the output price closely tracks the movement in marginal cost induced by material price changes.

Finally, Figure 7 gives the economy's response to a 1 percent increase in the preference parameter $\theta_{l}$ that dictates relative weights on goods and leisure. The increase in $\theta_{t}$ creates an expansion in hours and output of 1.2 and 0.8 percent respectively. Marginal cost increases initially by 0.4 percent, then gradually recedes with the labor-capital ratio. The markup falls, but only slightly. The reason is that movements in marginal cost induced by aggregate output fluctuations are largely reflected in prices to the extent they are mirrored by movements in the costs of entrants through the increase in economy-wide laborcapital ratio. Relatedly, if we reduce the autocorrelation of the shock from .9 to .2 , so that the increase in labor is much more transitory, then the markup falls by 2 percent in the first quarter of the shock.

The movement of the markup becomes quite dramatic, however, if we consider a demand disturbance that is industry-specific instead of economy-wide. In this case, price is unaffected by an industry-specific demand shock, because costs of entrants are not affected. This reflects the fact that the real interest rate is not affected. An increase in industry demand is met by a dramatic increase in labor-capital ratio, resulting in a large increase in marginal cost. We find, for a one percent increase in an industry's demand, that the industry markup of price over marginal cost decreases by about .5 percent.

\section{Pricing to Limit Non-price Competition}

There are several criticisms that can be leveled against the limit-pricing model of Section 3. Limit-pricing models are often criticized for assuming that entry can be achieved rather immediately and with little or no up front costs. Secondly, the outcome in the market is tightly linked to the behavior of costs for potential entrants. But given these potential entrants do not actually enter, the model is not readily empirically testable. Thirdly, and more directly linked to our purposes, the model does not necessarily generate rigid prices in response to fluctuations in aggregate demand and production. As seen in the previous section, in this case average costs for entrants may move nearly as much as marginal cost for the incumbent, causing price to move nearly as much as marginal cost. We now move to an 
alternative model of Bertrand competition allowing firms to compete with non-price features such as marketing for market share.

\section{Marketing Model}

Suppressing the industry index $j$ and time subscript, let there be $I$ firms with the same cost function, $g(y)$, producing a homogenous good in each industry. We assume these $I$ firms compete by simultaneously choosing price. Bertrand price competition among these firms would normally lead to a competitive outcome of price equal to marginal cost. But we add one other aspect to the pricing. Firms have the technology to post not only a price, but also to offer a guarantee to match other prices. Firms would in fact wish to include such a provision. So each firm, while posting a price $p(i)$, is in fact effectively setting the same price given by: $p=\min [p(i)]$, over $i=1$ to $l$. Each firm is in practice the market price setter in a downward direction, that is posting a price below others will result in all firms selling at that price. ${ }^{6}$

Suppose for the moment that, conditional on all firms charging the same price, market demand is divided equally among the $I$ firms; so each firm receives one $I^{\text {th }}$ of industry profits. Then each firm, essentially a market price setter, will have an incentive to post price at the price that maximizes industry profits. The Bertrand-competition result, of price equal to marginal cost, is replaced with price given by the perfectly collusive price. (Salop, 1985, and Edlin, 1997, discuss how such price guarantees actually raise prices by facilitating collusive outcomes.)

Our primary interest, however, is how such firms might attempt to influence market share through costly non-price competition. To motivate such competition, we start by assuming that a transaction requires some input of time from both the seller and customer. Let $m$ be the marketing labor per customer provided by the firm. Let $s$ be the shopping time

\footnotetext{
${ }^{6}$ We assume that firms have the technology to match not only other firms posted prices, but also other firms posted offers as a function of their own posted price. For example, if another firm posts an offer to beat firm $j$ 's price by amount $x$, it is understood that firm $j$ will match that price. This eliminates the incentive for other firms to make such an offer, as opposed to relying on their own posted price.
} 
provided by the customer. To accomplish a transaction, the two parties are required to provide sufficient labor to meet the constraint: $b(m, s)=1, b_{m}>0, b_{s}>0$. Of particular importance, the amount of time a consumer must spend shopping is decreasing in the seller's marketing or service effort, $s=s(m), s^{\prime}()<0$. In turn, this implies firms can compete for market share by increasing their choice of $m$. $m$ has several natural interpretations. By increasing marketing efforts, a seller provides information to buyers, reducing the effort required of the buyer to acquire information on prices and the availability of goods. By providing more sales clerks, a seller reduces the time required of a customer in finding items or waiting in lines. More generally, any quality dimension that competitors cannot explicitly match, as they can with posted prices, is a potential margin for non-price competition. ${ }^{7}$ For convenience, from here forward, we refer to $m(i)$ simply as firm i's marketing effort per customer. We denote firm $i$ 's total marketing effort by $M(i)$; it equals $m(i)$ times the number of buyers for firm $i$.

Since prices are the same across firms, consumers prefer to buy from the store with the highest marketing effort. This implies that consumers allocate themselves to sellers such as to equalize $m(i)$ across firms. This further implies that a firm's sales are proportional to its marketing effort, or, more exactly

$$
z(i)=D(p) \frac{M(i)}{\sum_{k=1, \ldots, I} M(k)}, \text { for } i=1, \ldots, I
$$

$z(i)$ is sales for firm $i$; and $D(p)$ is total industry demand at market price $p$.

Each firm has two choices: a choice of price and a choice of marketing effort. These choices can be viewed as a two-stage game. In the first stage firms choose price, aware that by choosing a lower price than other firms this lowers prices market wide (given the price matching). In the second stage firms choose marketing effort given $p$, the lowest posted price. It is convenient to consider these choices in reverse order.

Marketing effort $M(i)$ is chosen to maximize

\footnotetext{
${ }^{7}$ Carlton (1979) considers costly non-price competition through the size of inventories and length of delivery lags.
} 


$$
\max _{M(i)} p D(p) \frac{M(i)}{\sum_{k=1,, L} M(k)}-g\left(D(p) \frac{M(i)}{\sum_{k=1, ., L} M(k)}\right)-W M(i), \text { for } i=1, \ldots, I .
$$

Marketing effort reflects time; so the cost of marketing effort equals the wage $W$ times $M(i)$. Evaluated at the symmetric equilibrium, $M(i)=M(k)$, for all $k$. The optimal marketing expenditure $W M$ is

$$
W M=z(p)[p-m c(z(p))]\left(\frac{I-1}{I}\right) .
$$

$z(p)=D(p) / I$ is a typical firm's sales; and $m c(z(p))=g^{\prime}(z(p))$ is that typical firm's marginal cost.

Recall that each firm has the ability to lower the market price $p$. Substituting for $W M$ from (26), a firm's choice of price is dictated by

$$
\max _{p} z(p)[p-a c(z(p))]-\left(\frac{I-1}{I}\right) z(p)[p-m c(z(p))]
$$

Alternatively, we can write the firm's objective in choosing price as sales times a weighted average of price minus average cost of production and marginal cost minus average cost:

$$
\frac{1}{I} z(p)[p-a c(z(p))]+\left(\frac{I-1}{I}\right) z(p)[m c(z(p))-a c(z(p))] \text {. This reflects the fact that a high }
$$

marginal cost, given average cost, is desirable, as it reduces firms' expenditures on nonprice competition.

Price is set according to

$$
p=\frac{\varepsilon}{\varepsilon-1} m c(y)\left[1-(I-1) \frac{y m c^{\prime}(y)}{m c(y)}\right]
$$

where $\varepsilon$ is elasticity of market demand $\left(\varepsilon=\left|\frac{D^{\prime}(p) p}{D(p)}\right|\right), y(=z(p))$ is output, and $\frac{y m c^{\prime}(y)}{m c(y)}$ represents the elasticity of marginal cost with respect to output. If marginal cost is perfectly flat, then the presence of non-price competition has no impact on the market price. But, if marginal cost is upward sloping, then the presence of non-price competition unambiguously reduces the size of the markup. The intuition for this is as follows. By selecting a lower 
price a firm creates higher output for all firms. This, in turn, reduces costly non-price competition, not only due to the lower price, but also due to the higher marginal cost of sales. Note also that price markup is decreasing in the number of firms $(I)$, provided marginal cost is upward sloping.

Suppose production occurs under a CES production function with substitution elasticity $\sigma . y=a\left[\alpha l^{\frac{\sigma-1}{\sigma}}+(1-\alpha) k^{\frac{\sigma-1}{\sigma}}\right]^{\frac{\sigma}{\sigma-1}}$. Furthermore, let the number of firms be 2. Then, price in (28) simplifies to

$$
p=\left(\frac{\varepsilon}{\varepsilon-1}\right) m c(y)\left[1-\frac{1}{\sigma}\left(\frac{1-\alpha}{\alpha}\right)\left(\frac{l}{k}\right)^{\frac{1-\sigma}{\sigma}}\right] .
$$

For the Cobb-Douglas case the markup is simply a constant. But for $\sigma$ less than one the markup is countercyclical, in that it decreases with increases in the labor-capital ratio. We will see immediately below that the markup contains quite striking movements even for fairly small departures from Cobb-Douglas. Note that variations in factor prices or technology do not affect the elasticity of marginal cost with respect to output, so the markup of price over marginal cost is not affected. Thus this model has the potential to generate a larger price response to movements in marginal cost associated with factor prices than to movements in marginal cost generated by movements in the labor-capital ratio.

\section{Response to economy-wide shocks}

We again examine an economy's responses to aggregate shocks to technology and preferences, but now under this setting of firms pricing to limit costly non-price competition. The number of firms in each industry, $I$, is set equal to 2 . The substitution elasticity between production labor and capital, $\sigma$, is now set equal to 0.85 . (Hamermesh, 1986, offers a range of values for $\sigma$ from . 14 to 2.8. Lucas, 1969 , reports a range of values less than 0.8 .) We set the steady-state price markup ratio $\mu$ equal to 1.5 . For $\sigma=.85$, from equation (29), this requires a price elasticity of demand equal to 1.3784. This also implies, from equation (26), a steady-state ratio of "marketing labor" to production labor of $1 / 8$. The transaction technology is given by $b(m, s)=m^{0} s^{1-v}=1$; we set $v=0.5$ and $s$, the steady-state shopping 
time of consumers, equal to $1 / 24$, corresponding to 1 hour of shopping time per day. For these parameter values, in steady state, half of the profits generated by the markup of price over production cost is dissipated by firms through expenditures on "marketing labor". Profits, as a share of total revenue, equal $16.7 \%$.

Figure 8 presents the economy's response to a 1 percent positive shock to technology. Output increases by 1.4 percent, with much of it occurring through investment. Marginal cost falls by less than one percent (relative to the wage) reflecting the increase in the labor-capital ratio. Because of the convexity of marginal cost, the markup falls, but by less than 2 percent. The dramatic increase in investment, combined with the rapid retreat in production labor, causes the ratio of production labor to capital to actually decrease by about a year into the expansion. Consequently, the price markup moves from below to above trend. Reflecting the behavior of the markup, sales (marketing) labor increases much less initially than production labor, but soon overtakes the increase in production labor.

The last figure, Figure 9, displays the economy's response to a positive shock of 1 percent to the preference parameter. The economy exhibits a substantial expansion in hours, output, and consumption, with production labor increasing by 1.5 percent and output by 1 percent. Marginal cost increases with the sustained expansion in the labor-capital ratio. The model is very successful, however, in muting the response of price to this movement in marginal cost-a fall in the price markup offsets about two-thirds of the increase in marginal cost. For instance, in the first quarter marginal cost increases by 0.6 percent, but price by only 0.2 percent. This fall in the markup results in a response of output to the preference shock that is about 25 percent larger in magnitude than for a comparable economy with no variation in markup. Directly related to the fall in the markup, employment of marketing labor expands by only about a third as much as does production labor.

This model is clearly capable of generating a relatively weak response of price to fluctuations in marginal cost associated with variations in output and the labor-capital ratio, as found in Section 2. This is true even though we entertain a relatively small departure from Cobb Douglas production $(\sigma=.85)$. The model is also suggestive of the result from Section 2 of a weaker response in price when non-production workers are more important. Finally, the greater volatility of production to non-production workers exhibited in Figure 9 is clearly supported by the data (Oi, 1962, and many others). 


\section{Conclusions}

The role of sticky prices in business cycle fluctuations has been discussed and disputed for many years. We argue, however, that it is important to distinguish between the nature of the shocks in describing how prices respond. In examining disaggregate U.S. manufacturing data, we confirm results from the empirical pricing literature of 1950's and 1960's that prices respond more dramatically to an increase in costs driven by factor prices than to an increase in marginal cost precipitated by an expansion in output. But we also find that prices respond considerably more to cost increases due to increases in material or energy prices than to those due to increases in wage rates or decreases in productivity. Finally, we find that the response of industry price to fluctuations in production is particularly weak in industries with concentrated production.

We explore two models we see with potential to explain why price might respond dramatically to factor prices, yet respond weakly to marginal cost more generally. The first is a limit-pricing model. The key is that price is dictated by average costs of potential entrants rather than the producer's marginal cost. It turns out, however, that for a sustained aggregate increase in production, this model predicts that prices do largely track fluctuations in marginal cost. A persistent aggregate shock to the economy not only drives up the producers' marginal costs, but also drives up the average cost of entrants by increasing the cost of capital. The model might be helpful, however, in explaining the weaker response to wage rates and TFP than for other cost factors. If fluctuations in wages and productivity for producers are not mirrored by similar fluctuations for potential entrants, then changes in these factors will not be passed through into prices.

We introduce a model in which firms limit prices because they recognize a high market price, though directly raising profits, will induce all the firms in the market to dissipate those profits through costly non-price competition such as advertising and marketing. Although price is a markup over marginal cost, the size of this markup also depends on the slope of marginal cost. If expanded production is associated not only with an increase in marginal cost, but also with an increase in the elasticity of marginal cost with respect to output, then the increase in marginal cost is offset by a drop in the markup. We 
show such a drop in the markup occurs provided the elasticity of substitution between capital and labor is less than one. Furthermore, we show for a case in which the elasticity of substitution is fairly close to one that this effect can mute much of the impact on price of a cyclical increase in marginal cost. We view this model as promising for explaining many of our empirical findings on cyclical pricing. 


\section{Appendix: Varying capital utilization and overheal inputs}

In the text we allow for movements in industry TFP arising from non-constant returns as well as shifts in technology. In either scenario price should grow one percent less for each one percent increase in TFP. In this appendix, we explore the robustness of this prediction to TFP movements that reflect varying utilization of capital or increasing returns due to overhead inputs of labor and capital.

It has often been suggested that cyclical movements in TFP reflect procyclical, unmeasured, variations in the utilization of inputs, particularly capital. If we allow the production of value added to be a function of utilized capital, $h_{k} k$, where $h_{k}$ is a measure of the workweek of capital, then (2) becomes

$$
\nu=\left[\alpha n^{\frac{\sigma-1}{\sigma}}+(1-\alpha)\left(h_{k} k\right)^{\frac{\sigma-1}{\sigma}}\right]^{\frac{(1+\eta) \sigma}{\sigma-1}} .
$$

Following Lucas (1970), Shapiro (1995), and Bils and Klenow (1998), we assume the cost of increased utilization of capital is reflected in extra pay for workers in the form of shift premia for working later shifts. We write the wage bill per hour as $w=w_{0} h_{k}^{\phi}$. Given (A1), this implies a choice for $h_{k}$

$$
h_{k}=\frac{n}{k}\left(\frac{1-\alpha}{\phi \alpha}\right)^{\frac{\sigma}{1-\sigma}}
$$

The rate of growth in the shadow price of value added is now given by

$$
\hat{p}_{v}=\hat{w}+\left(\frac{s_{k}}{s_{n}+s_{k}}\right)\left(\frac{\hat{n}}{k}\right)-\left(\eta\left(\frac{s_{n} \hat{n}+s_{k} \hat{k}}{s_{n}+s_{k}}\right)+(1+\eta)\left(\frac{s_{k}}{s_{n}+s_{k}}\right)\left(\frac{\hat{n}}{k}\right)\right) .
$$

Comparing to equation (4), a varying $h_{k}$ has three impacts. The growth rate in the wage now reflects variations in shift premium. The term in brackets reflects both increasing returns and variations in the utilization rate of capital. This term is captured one-for-one by including the growth rate of measured TFP in the pricing equation, where TFP is measured assuming constant returns and (incorrectly) a constant rate of capital utilization. Finally, the coefficient on $\left(\frac{s_{k}}{s_{n}+s_{k}}\right)\left(\frac{\hat{n}}{k}\right)$ is now simply 1 , instead of $1 / \sigma$. With varying capital utilization, 
production behaves as though Cobb-Douglas even if $\sigma$ does not equal one. It is also the case that capital's share relative to labor's is constant, equaling $\phi$, even if $\sigma$ is not 1 .

The upshot is that variations in capital utilization do not explain the results for price changes above that: changes in TFP have an impact of much less in magnitude than -1 ; and changes in $s_{k}(\hat{n})$ have an impact of much less than 1 .

Suppose increasing returns arise from overhead inputs of labor and capital being spread over more variable units in an expansion. In this case an expansion is associated with an increase in measured TFP, but without a corresponding decline in marginal cost. This is not able, however, to explain the relatively small coefficient on TFP growth in the price equation. Denote the overhead inputs of labor and capital as $\bar{n}$ and $\bar{k}$. The net result of ignoring these terms in our treatment above is to add the following terms to the error in the price equation:

$$
\left(1-\mu s_{m}\right)\left(\frac{\bar{n}}{n-\bar{n}}\right) \hat{n}+\frac{\sigma-1}{\sigma}\left(1-\mu s_{m}\right)\left(\frac{s_{k}}{s_{n}+s_{k}}\right)\left[\left(\frac{\bar{n}}{n-\bar{n}}\right) \hat{n}-\left(\frac{\bar{k}}{k-\bar{k}}\right) \hat{k}\right] .
$$

These terms will be highly positively correlated with the term $\frac{1}{\sigma}\left(1-\mu s_{m}\right)\left(\frac{s_{k}}{s_{n}+s_{k}}\right)\left(\frac{n}{k}\right)$, which is in the price equation. For example, under Cobb-Douglas production the terms reduce to the first: $\left(1-\mu s_{m}\right) \frac{\bar{n}}{n-\bar{n}} \hat{n}$. The correlation between $\hat{n}$ and $\left(\frac{n}{k}\right)$ in our data is 90 reflecting the fact that the capital stock, being a stock, is much less volatile than labor hours. This implies that ignoring overhead factors should largely have the effect of biasing upward the coefficient on $\left(\frac{\hat{n}}{k}\right)$ in the price equation. But as we discussed above, the problem is that this estimated coefficient is actually much too small. 


\section{References}

Bartelsman, E. J., and Gray, W.

(1996) The NBER Manufacturing Productivity Database. NBER Technical Working Paper No. 205.

Basu, S., and Fernald, G.

(1997) Returns to Scale in U.S. Production: Estimates and Implications. Journal of Political Economy, 105: 249-283.

Basu, S., Fernald, G., and Kimball, M.

(1998) Are Technology Improvements Contractionary? Manuscript, University of Michigan.

Bils, M.

(1987) The Cyclical Behavior of Marginal Cost and Price. American Economic Review, 77: 838-857.

Bils, M., and Klenow, P.

(1998) Using Consumer Theory to Test Competing Business Cycle Models. Journal of Political Economy, 106: 233-261.

Blanchard, $\mathrm{O}$.

(1987) Aggregate and Individual Price Adjustment. Brookings Papers on Economic Activity, 1:57-109.

Blinder, A.

(1994) On Sticky Prices: Academic Theories Meet the Real World. Monetary Policy. N. G. Mankiw, ed., Chicago: University of Chicago Press.

Bodkin, R. G.

(1966) The Wage-Price-Productivity Nexus. Philadelphia: University of 
Pennsylvania Press.

Carlton, D.

(1979) Contracts, Price Rigidity, and Market Equilibrium. Journal of Political Economy, 87: 1034-1062.

Carlton, D.

(1986) The Rigidity of Prices. American Economic Review, 76: 637-658.

Cecchetti, S.

(1986) The Frequency of Price Adjustment: A Study of the Newstand Prices of Magazines, 1953 to 1979. Jomrnal of Econometrics, 31:255-74.

Dow, J. C. R.

(1956) The Analysis of the Generation of Price Inflation Oxford Economic Papers, 8.

Eckstein, O., and Fromm, G.

(1968) The Price Equation. American Economic Review, 58: 1159-1183.

Edlin, A.

(1997) Do Guaranteed-Low Price Policies Guarantee High Prices, and Can Antitrust Rise to the Challenge? Harvard Law Review, 111: 528-575.

Gali, J.

(1999) Technology, Employment, and the Business Cycle: Do Technology Shocks Explain Aggregate Fluctuations? American Economic Review, 89: $249-271$.

Hall, R. E.

(1980) Employment Fluctuations and Wage Rigidity. Brookings Papers on Economic Activity, 1: 93-123.

Hall, R. E. 
(1988) The Relation between Price and Marginal Cost in U.S. Industry. Joumal of Political Economy, 96: 921-947.

Hall, R. E.

(1991) Labor Demand, Labor Supply, and Employment Volatility. NBER Macroeconomics Ammal 6: 17-54.

Hall, R. L. and Hitch, C. J.

(1939) Price Theory and Business Behavior. Oxford Economic Papers, 2:12-45. Hamermesh, D.

(1986) The Demand for Labor in the Long Run. Handbook of Labor Economics, Vol. I, 429-471, eds. O. Ashenfelter and R. Layard, Amsterdam: NorthHolland.

Kaplan, A., Dirlam, J., and Lanzilotti, R.

(1958) Pricing in Big Business-a Case Approach, Washington.

Kashyap, A.

(1995) Sticky Prices: New Evidence from Retail Catalogs. Quarterly Journal of Economics, 110: 245-274.

Klein, L., and Ball, R.

(1959) Some Econometrics of the Determination of Absolute Prices and Wages. Economic Journal, 69: 465-482.

Kuh, E.

(1959) Profits, Profit Markups and Productivity. Study of Employment, Growth and Price Levels. Washington: U.S. Congress.

Lucas, R. E.

(1967) Adjustment Costs and the Theory of Supply. Journal of Political Economy, 75: 321-334. 
Lucas, R. E.

(1969) Labor-Capital Substitution in U.S. Manufacturing. The Taxation of Income from Capital. eds. A. Harberger and M. Baily. Washington: Brookings Institution.

Lucas, R. E.

(1970) Capacity, Overtime, and Empirical Production Functions. American

Economic Review, 60: 23-27.

McCallum, B. T.

(1969) Formulating and Testing of the Target Return Pricing Hypothesis.

Ph.D. thesis, Rice University.

Modigliani, F.

(1958) New Developments on the Oligopoly Front. Journal of Political Economy, 66: $215-232$.

Neild, R. R.

(1963) Pricing and Employnent in the Trade Cycle. Cambridge, England.

Oi, W.

(1962) Labor as a Quasi-fixed Factor. Jomrnal of Political Economy, 70: 538-555.

Roberts, J., Stockton, D., and Struckmeyer, C.

(1994) Evidence on the Flexibility of Prices. Review of Economics and Statistics, $142-150$.

Rotemberg, J.

(1982a) Monopolistic Price Adjustment and Aggregate Output. Review of Economic Studies, 49: 517-531.

Rotemberg, $\mathbf{J}$.

(1982b) Sticky Prices in the United States. Jomrnal of Political Economy, 
90: $1187-1211$.

Rotemberg, J.

(1983) Aggregate Consequences of Fixed Costs of Changing Prices. American Economic Review, 73: 433-436.

Rotemberg, J., and Woodford, M.

(1991) Markups and the Business Cycle. NBER Macroeconomics Anmual, 63-129.

Rotemberg, J., and Woodford, M.

(1995) Dynamic General Equilibrium Models with Imperfectly Competitive Markets. Frontiers of Business Cycle Research. eds. Thomas Cooley, Princeton: Princeton University Press.

Salop, S.

(1985) Practices that (Credibly) Facilitate Oligopoly Coordination. New Developments in the Analysis of Market Structure. eds. J. E. Stiglitz and F. Mathewson. Cambridge, MA: MIT Press.

Sbordone, A.

(1998) Prices and Unit Labor Costs: Testing Models of Pricing Behavior. manuscript, Princeton University.

Shapiro, M.

(1995) Capital Utilization and the Marginal Premium for Work at Night. manuscript, University of Michigan.

Shea, J.

(1993) Do Supply Curves Slope Up? Quarterly Journal of Economics, 108: $1-32$.

Stigler, G. J. 
(1967) Price and Non-Price Competition. Jonrnal of Political Economy, 76: 149-154.

Sylos Labini, P.

(1957) Olipopolio e progresso tecnico. Milan.

Wilson, T.A.

(1959) An Analysis of the Inflation in Machinery Prices. Study of Employment, Growth and Price Levels. Washington: U.S. Congress.

Zarnowitz, V.

(1962) Unfilled Orders, Price Changes, and Business Fluctuations. Review of Economics and Statistics, 44: 367-394. 
</ref_section> 
Table 1. The Response of Price to Factors*: Dependent variable is $\hat{p}$.

\begin{tabular}{|c|c|c|c|c|}
\hline & Column 1 & Column 2 & Column 3 & Column 4 \\
\hline$T \hat{F P}$ & & $\begin{array}{c}-.51 \\
(.005)\end{array}$ & $\begin{array}{c}-.51 \\
(.005)\end{array}$ & $\begin{array}{c}-.51 \\
(.026)\end{array}$ \\
\hline$S_{m} \hat{p}_{m}$ & $\begin{array}{c}1.08 \\
(.013)\end{array}$ & $\begin{array}{c}1.09 \\
(.010)\end{array}$ & & $\begin{array}{r}1.17 \\
(.030)\end{array}$ \\
\hline$s_{m^{\prime}} \hat{p}_{m^{\prime}}$ & & & $\begin{array}{c}1.09 \\
(.010)\end{array}$ & \\
\hline$S_{\text {energy }} \hat{p}_{\text {energy }}$ & & & $\begin{array}{c}.94 \\
(.086)\end{array}$ & \\
\hline$\left(1-s_{m}\right) \hat{w}$ & $\begin{array}{c}.17 \\
(.016)\end{array}$ & $\begin{array}{c}.49 \\
(.013)\end{array}$ & $\begin{array}{c}.49 \\
(.013)\end{array}$ & $\begin{array}{c}.74 \\
(.062)\end{array}$ \\
\hline$s_{k}\left(\frac{\hat{n}}{k}\right)$ & $\begin{array}{c}.07 \\
(.015)\end{array}$ & $\begin{array}{c}.54 \\
(.012)\end{array}$ & $\begin{array}{c}.53 \\
(.012)\end{array}$ & $\begin{array}{c}.65 \\
(.064)\end{array}$ \\
\hline $\bar{R}^{2}$ & .30 & .61 & .61 & .77 \\
\hline \# of observations & 16,444 & 16,444 & 16,444 & 720 \\
\hline
\end{tabular}

* Estimation is by weighted least squares. Regressions include time dummies. Standard errors are in parentheses. The $\bar{R}^{2}$ is net of the time dummies. 
Table 2. The Variables' Standard Deviations and Autocorrelation Coefficients*

\begin{tabular}{lcc}
\hline & $\begin{array}{l}\text { Standard } \\
\text { Deviation }\end{array}$ & $\begin{array}{l}\text { Autocorrelation } \\
\text { Coefficient }\end{array}$ \\
\hline$\hat{p}$ & 5.2 & $\begin{array}{c}.20 \\
(.008)\end{array}$ \\
$T \hat{F P}$ & 6.1 & -.01 \\
& & $(.008)$ \\
$s_{m} \hat{p}_{m}$ & 2.7 & .12 \\
$\left(1-s_{m}\right) \hat{w}$ & & $(.008)$ \\
& 2.1 & -.06 \\
$s_{k}\left(\frac{n}{k}\right)$ & & $(.008)$ \\
$m$ & 2.3 & .08 \\
$m$ & & $(.008)$
\end{tabular}

* All variables are relative to time-period averages across the 458 industries. 
Table 3. The Response of Price to Factors varying the markup*: Dependent variable is $\hat{p}$.

\begin{tabular}{|c|c|c|c|}
\hline & $\mu=1$ & $\mu=1.25$ & $\mu=1.5$ \\
\hline$T \hat{F P}$ & $\begin{array}{c}-.51 \\
(.005)\end{array}$ & $\begin{array}{l}-.52 \\
(.004)\end{array}$ & $\begin{array}{r}-.49 \\
(.004)\end{array}$ \\
\hline$\mu s_{m} \hat{p}_{m}$ & $\begin{array}{l}1.09 \\
(.010)\end{array}$ & $\begin{array}{c}.92 \\
(.008)\end{array}$ & $\begin{array}{c}.80 \\
(.006)\end{array}$ \\
\hline$\left(1-\mu S_{m}\right) \hat{w}$ & $\begin{array}{c}.49 \\
(.012)\end{array}$ & $\begin{array}{c}.50 \\
(.014)\end{array}$ & $\begin{array}{c}.51 \\
(.015)\end{array}$ \\
\hline$\left(1-\mu s_{m}\right) \frac{s_{k}}{s_{n}+s_{k}}\left(\frac{\hat{n}}{k}\right)$ & $\begin{array}{c}.54 \\
(.012)\end{array}$ & $\begin{array}{c}.51 \\
(.014)\end{array}$ & $\begin{array}{c}.44 \\
(.018)\end{array}$ \\
\hline $\bar{R}^{2}$ & .61 & .62 & .61 \\
\hline \# of observations & 16,444 & 16,444 & 16,444 \\
\hline
\end{tabular}

* Estimation is by weighted least squares. Regressions include time dummies. Standard errors are in parentheses. The $\bar{R}^{2}$ is net of the time dummies. 
Table 4. The Response of Price to Current and Future Prices*:

Dependent variable is $\hat{p}$.

\begin{tabular}{lcc}
\hline & Column 1 & Column 2 \\
& & .09 \\
\hline$\hat{p}(t-1)$ & .07 & $(.005)$ \\
& $(.005)$ & .10 \\
$E_{t}[\hat{p}(t+1)]$ & & $(.005)$ \\
& & -.51 \\
$T \hat{F} P$ & -.51 & $(.005)$ \\
& $(.005)$ & 1.04 \\
$s_{m} \hat{p}_{m}$ & 1.08 & $(.010)$ \\
& $(.010)$ & .47 \\
$\left(1-s_{m}\right) \hat{w}$ & .48 & $(.013)$ \\
& $(.013)$ & .52 \\
$s_{k}\left(\frac{n}{k}\right)$ & .53 & $(.013)$ \\
$\bar{R}^{2}$ & $(.012)$ & .64 \\
$\#$ of observations & 15,994 & 15,022 \\
\hline m & .62 &
\end{tabular}

* Estimation is by weighted least squares in Column 1 and by weighted 2sls in Column 2. 
Table 5. The Response of Price to $s_{k}\left(\frac{\hat{n}}{k}\right)$ by Industry*: Dependent variable is $\hat{p}$.

\begin{tabular}{|c|c|}
\hline Industry & Coefficient for $s_{k}\left(\frac{\hat{n}}{k}\right)$ \\
\hline Primary Metals & $.94(.085)$ \\
\hline Lumber & $.77(.096)$ \\
\hline Food & $.72(.048)$ \\
\hline Petroleum & $.67(.141)$ \\
\hline Textiles & $.61 \quad(.056)$ \\
\hline Paper & $.59(.083)$ \\
\hline Leather & $.52(.083)$ \\
\hline Nonelectrical Machinery & $.52(.029)$ \\
\hline Rubber & $.52(.054)$ \\
\hline Chemicals & $.45(.040)$ \\
\hline Transportation Equipment & $.41 \quad(.048)$ \\
\hline Miscellaneous Durables & $.41 \quad(.050)$ \\
\hline Stone, Glass, \& Clay & $.39(.041)$ \\
\hline Electrical Machinery & $.35(.036)$ \\
\hline Apparel & $.33 \quad(.039)$ \\
\hline Instruments & $.33(.037)$ \\
\hline Fabricated Metals & $.30(.036)$ \\
\hline Tobacco & $.29(.124)$ \\
\hline Printing & $.23(.042)$ \\
\hline Furniture & $.22(.044)$ \\
\hline
\end{tabular}


Table 6. The Response of Price to $s_{k}\left(\frac{\hat{n}}{k}\right)$ by Industry Characteristics*:

Dependent variable is $\hat{p}$.

\begin{tabular}{|c|c|c|}
\hline & Column 1 & Column 2 \\
\hline$T \hat{F P}$ & $\begin{array}{l}-.51 \\
(.005)\end{array}$ & $\begin{array}{c}-.51 \\
(.005)\end{array}$ \\
\hline$s_{m} \hat{p}_{m}$ & $\begin{array}{l}1.06 \\
(.010)\end{array}$ & $\begin{array}{r}1.06 \\
(.010)\end{array}$ \\
\hline$\left(1-s_{m}\right) \hat{w}$ & $\begin{array}{c}.51 \\
(.014)\end{array}$ & $\begin{array}{c}.51 \\
(.014)\end{array}$ \\
\hline$s_{k}\left(\frac{\hat{n}}{k}\right)$ & $\begin{array}{c}.55 \\
(.014)\end{array}$ & $\begin{array}{c}.56 \\
(.014)\end{array}$ \\
\hline$s_{k}\left(\frac{\hat{n}}{k}\right) \cdot C R$ & $\begin{array}{l}-.28 \\
(.056)\end{array}$ & $\begin{array}{l}-.27 \\
(.056)\end{array}$ \\
\hline$s_{k}\left(\frac{\hat{n}}{k}\right) \cdot N P S$ & & $\begin{array}{l}-.12 \\
(.104)\end{array}$ \\
\hline $\bar{R}^{2}$ & .60 & .60 \\
\hline \# of observations & 14,041 & 14,041 \\
\hline
\end{tabular}

* Estimation is by weighted least squares. $C R$ denotes the deviation of the industry's concentration ratio from .40; NPS denotes the deviation of the industry's non-production employment share from .25 . 
Table 7. Parameter Values for the Benchmark Case

\begin{tabular}{ll}
\hline Parameters & Description \\
\hline$\alpha=2 / 3$ & Labor share in output \\
$\delta=0.99$ & Discount factor \\
$N=1 / 3$ & Depreciation rate \\
$\gamma=2$ & curvature in leisure in preference \\
$\theta=0.594$ & Steady-state value in preference \\
$\sigma=.85$ & substitution elasticity between production labor and capital \\
$\mu=1.5$ & in the marketing model \\
$\varepsilon=1.3784$ & Steady state value of markup \\
I $=2$ & Number of firms in the industry in the marketing model \\
\hline
\end{tabular}


Figure 1. Equilibrium under limit pricing

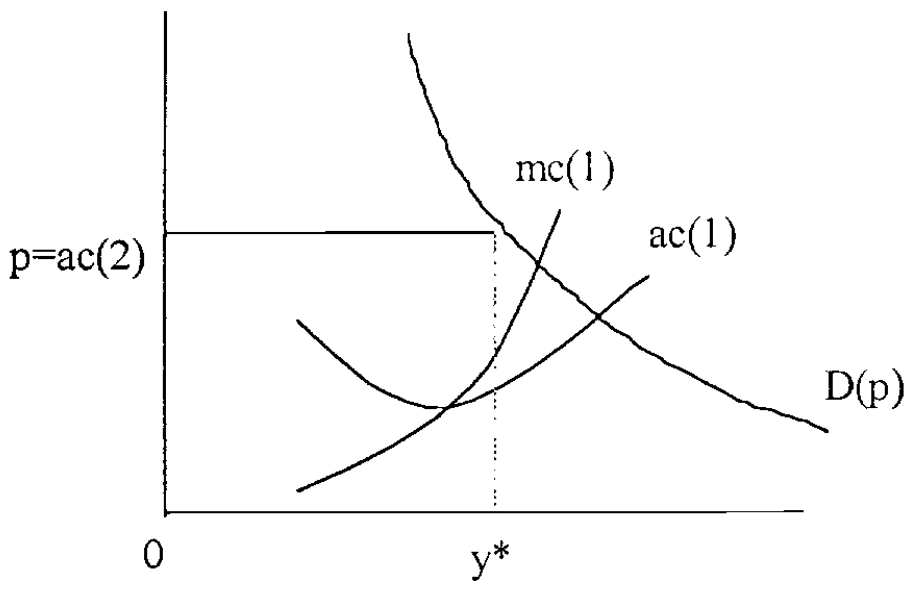


Figure 2. Productivity increase of the fringe firm

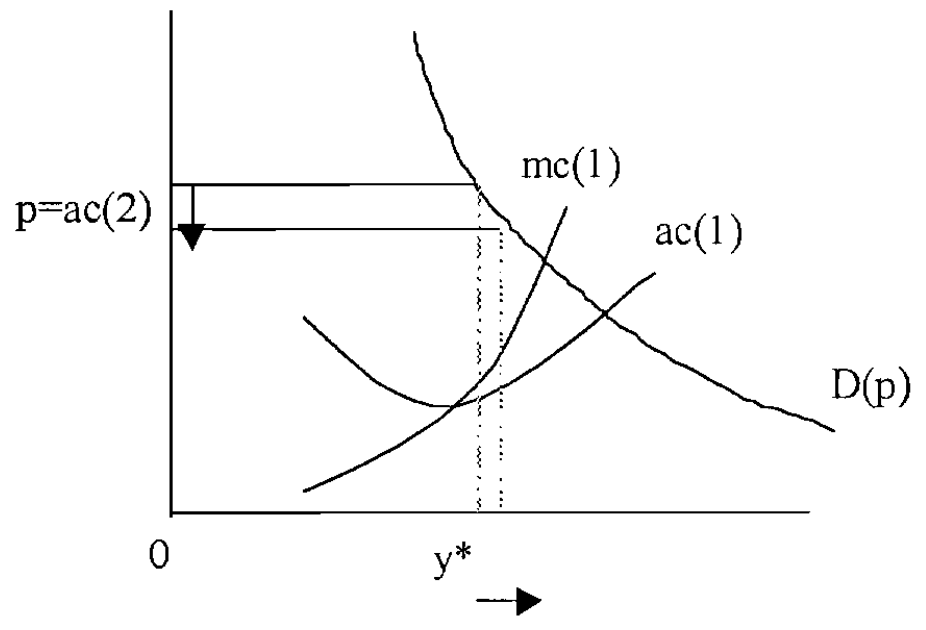

Figure 3. Productivity increase of the incumbent firm

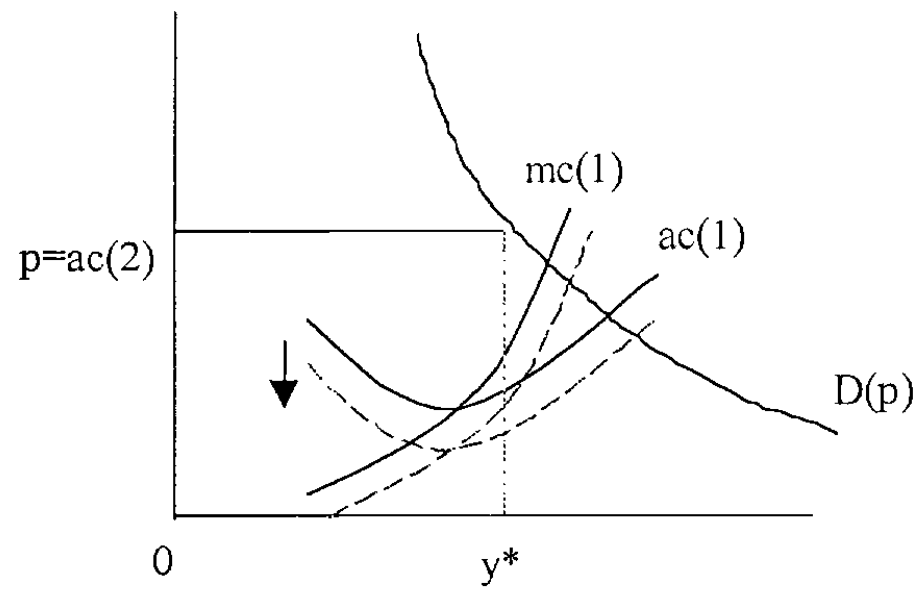


Figure 4. Productivity increase of both incumbent and fringe firm: limit-pricing
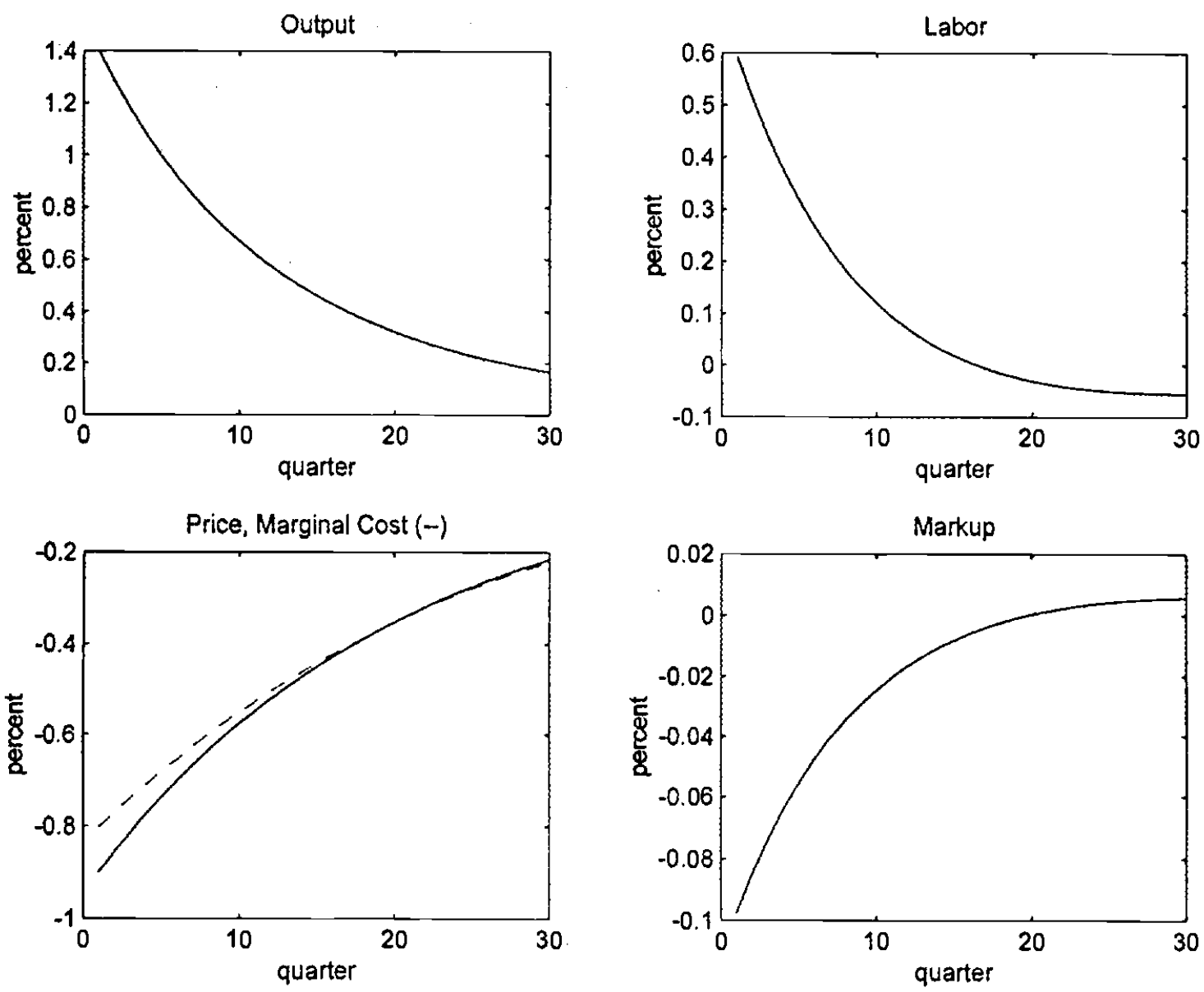
Figure 5. Productivity increase of the incumbent firm: limit-pricing
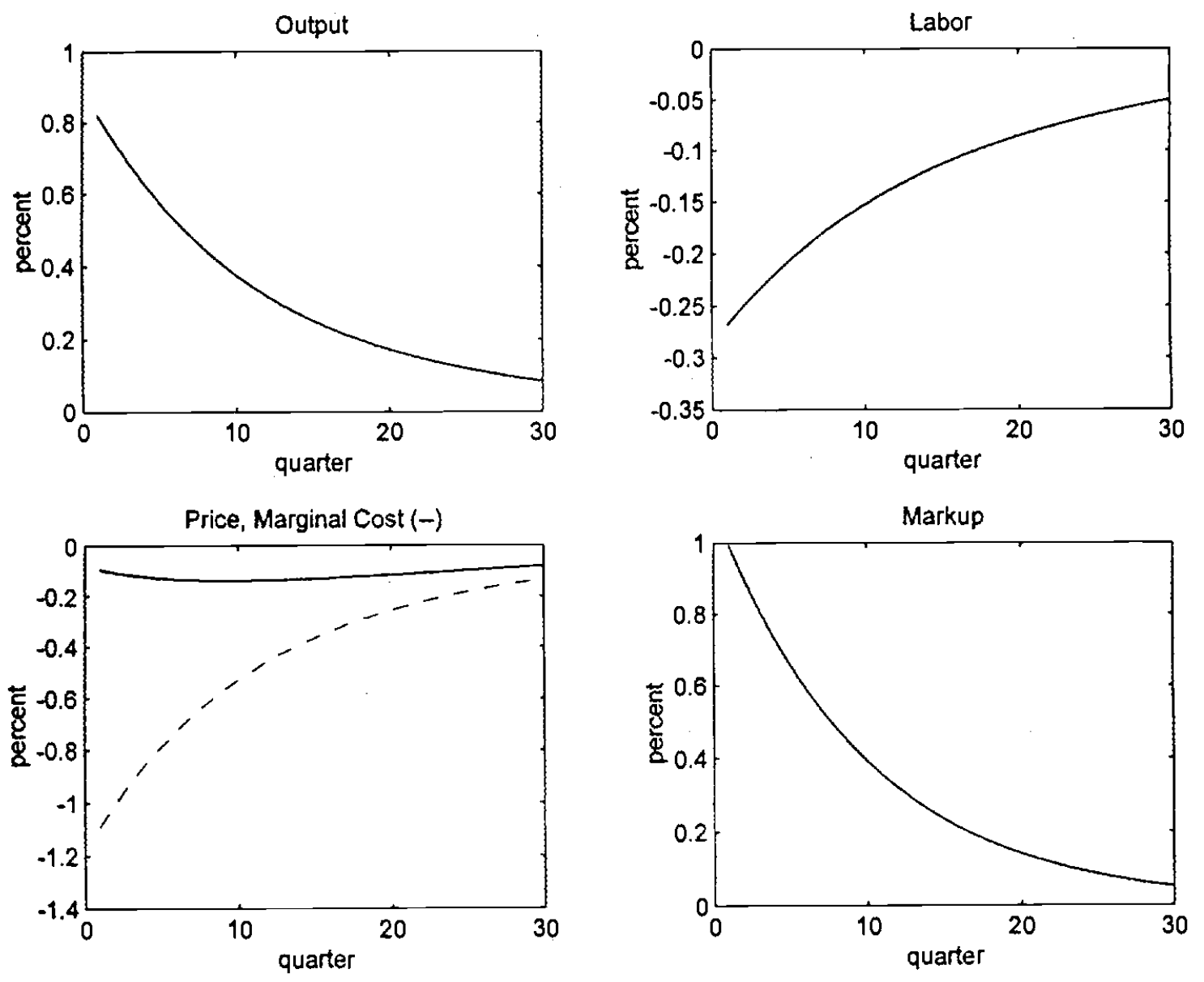
Figure 6. Productivity increase of the fringe firm: limit-pricing
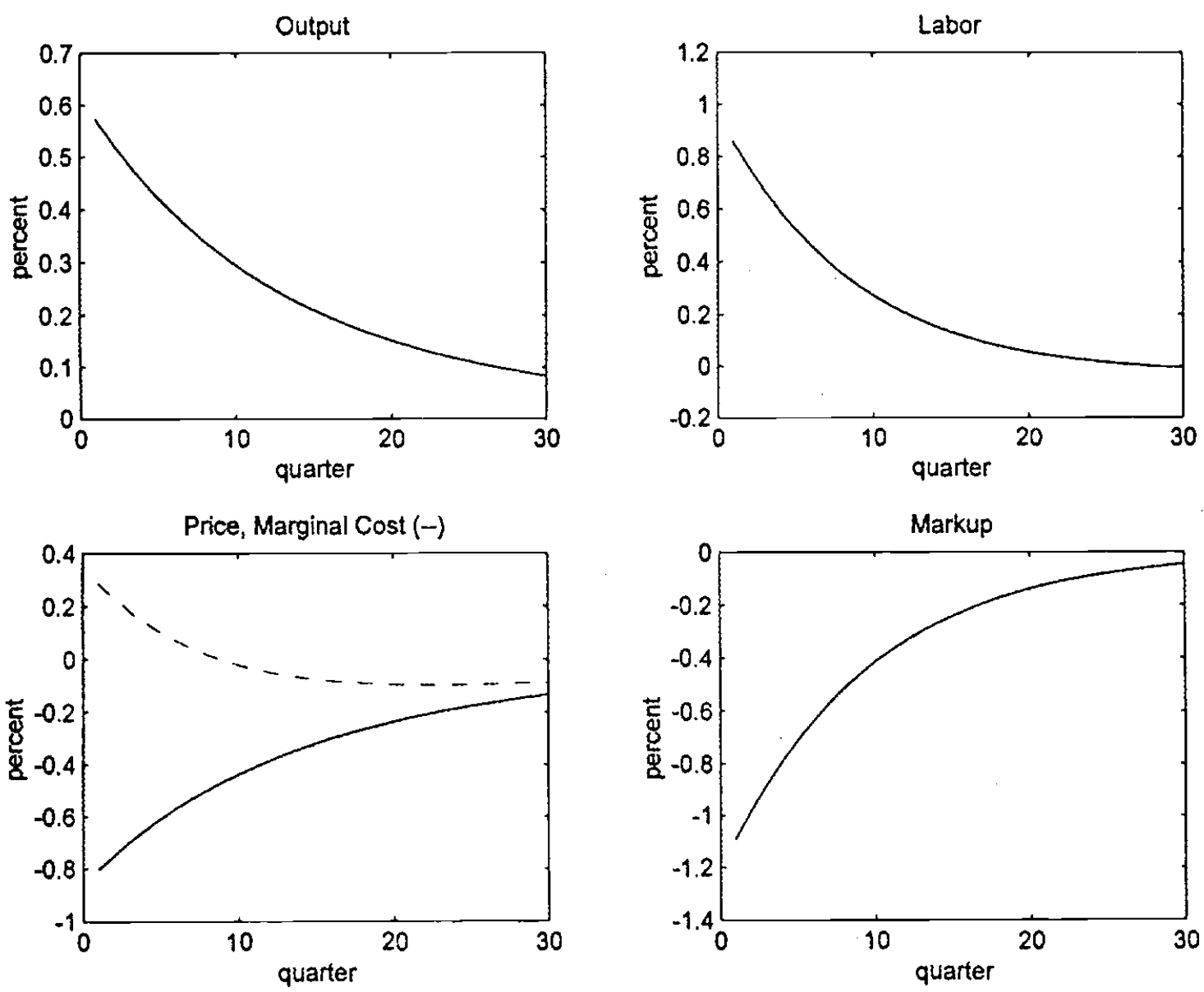
Figure 7. Positive preference shock: limit-pricing
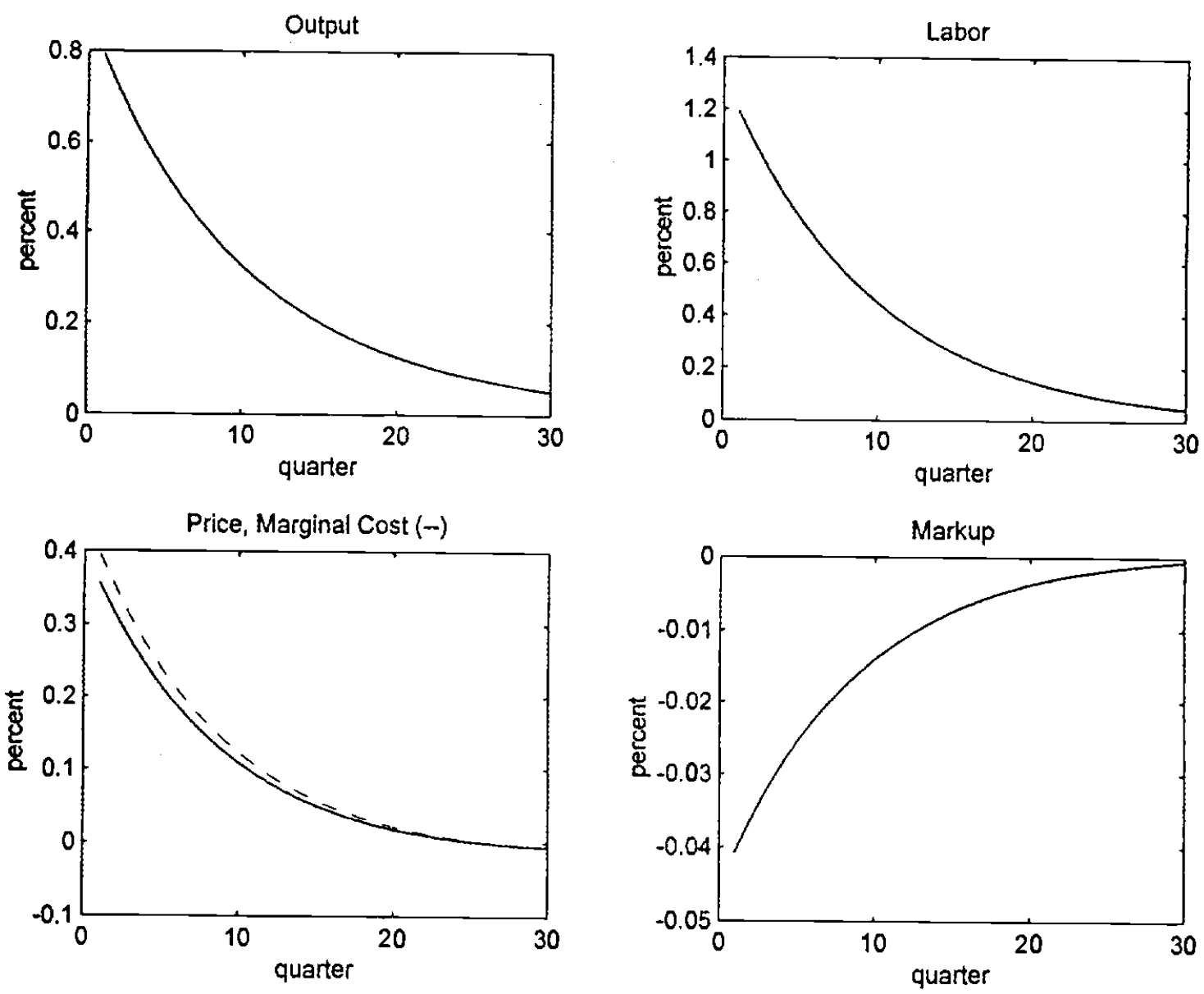
Figure 8. Productivity increase: marketing model
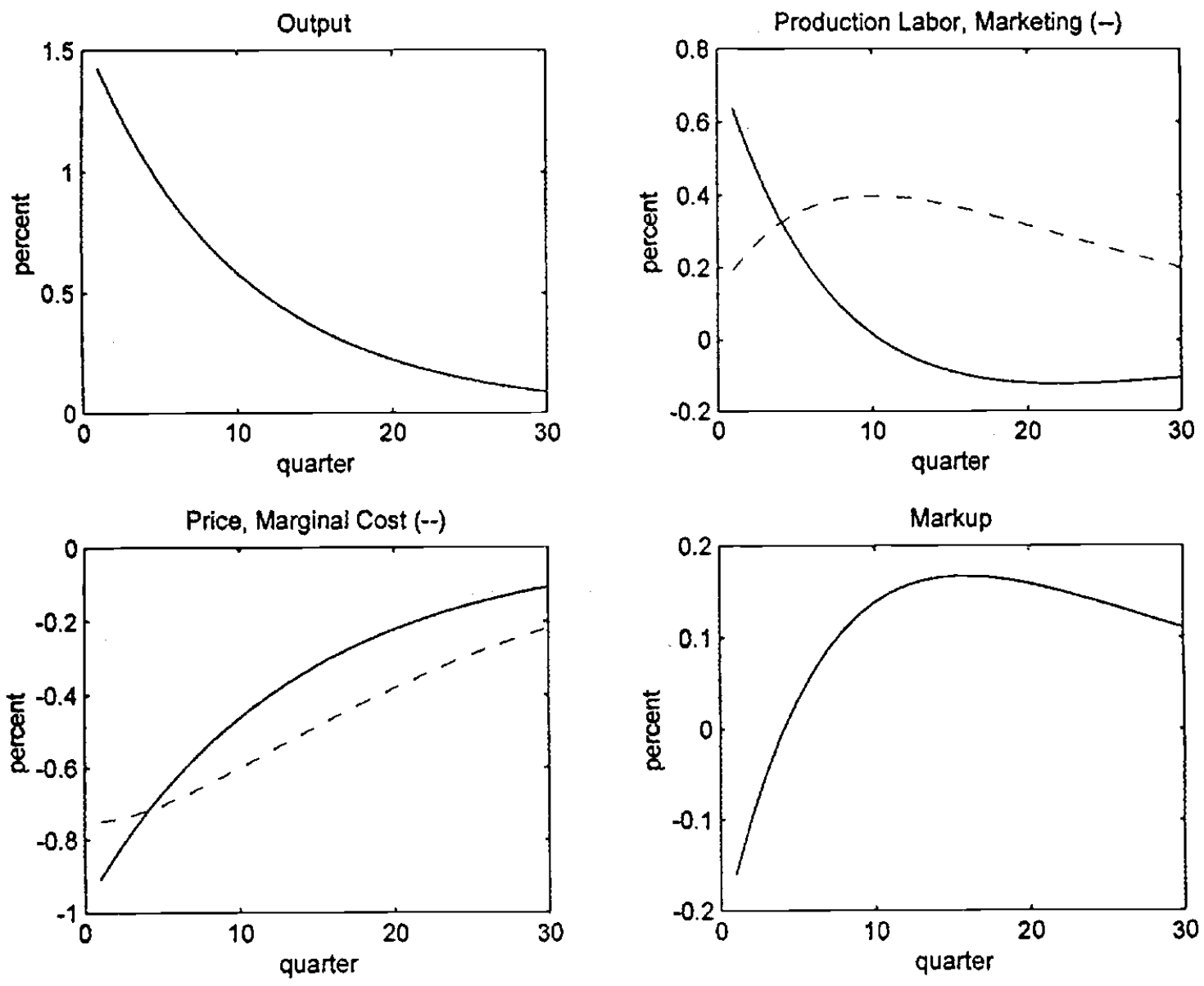
Figure 9. Positive preference shock: marketing model
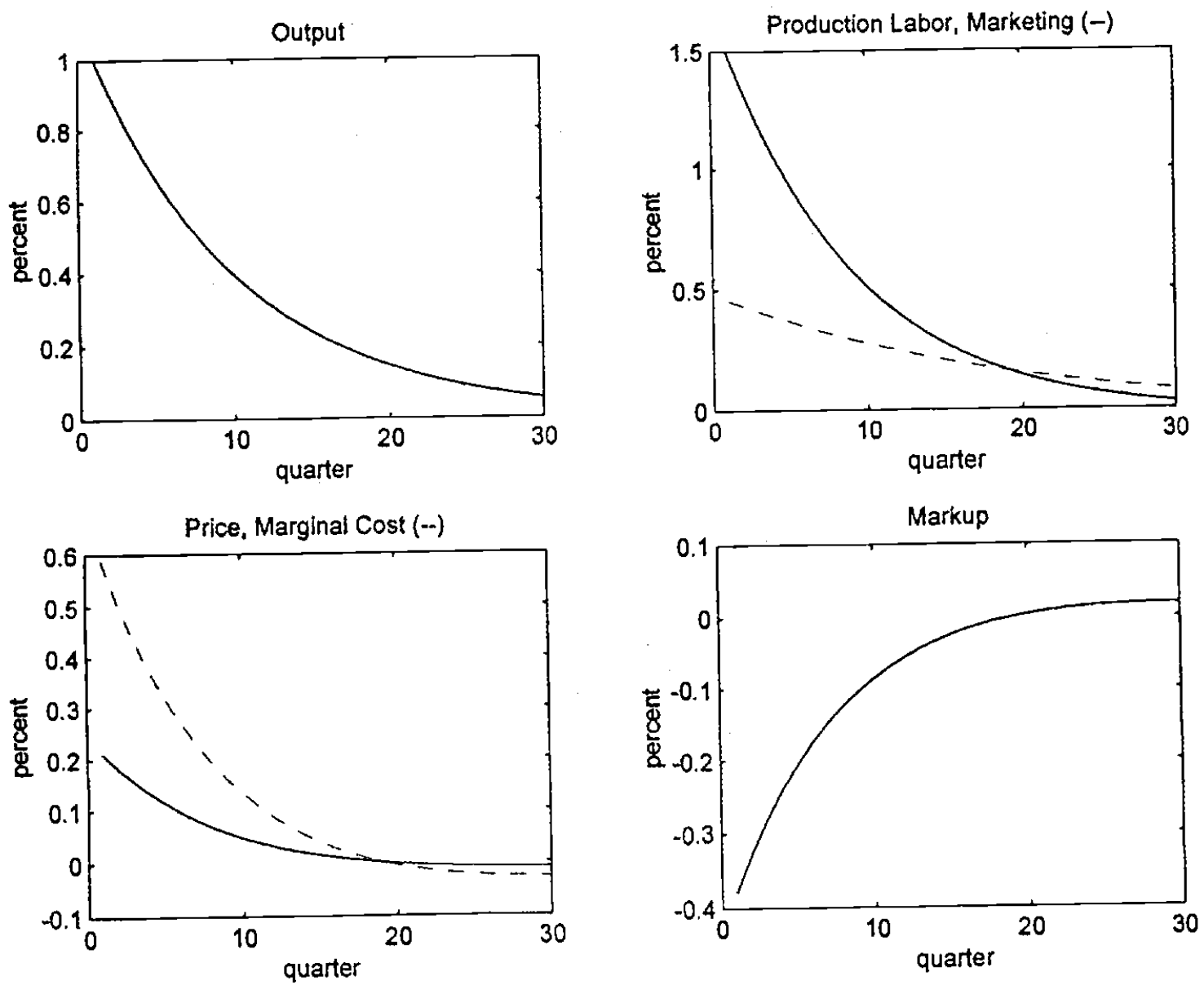